Cite this: Energy Environ. Sci., 2014, 7, 482

\title{
Energy demand and emissions of the non-energy sector
}

\author{
Vassilis Daioglou, ${ }^{* a b}$ Andre P. C. Faaij, ${ }^{a}$ Deger Saygin, ${ }^{a}$ Martin K. Patel, $\uparrow^{\mathrm{c}}$ Birka Wicke $^{\mathrm{a}}$ \\ and Detlef P. van Vuuren ${ }^{\mathrm{ab}}$
}

The demand for fossil fuels for non-energy purposes such as production of bulk chemicals is poorly understood. In this study we analyse data on non-energy demand and disaggregate it across key services or products. We construct a simulation model for the main products of non-energy use and project the global demand for primary fuels used as feedstocks and the resulting carbon emissions until 2100. The model is then applied to estimate the potential emission reductions by increased use of biomass, a more ambitious climate policy and advanced post-consumer waste management. We project that the global gross demand for feedstocks more than triples from $30 \mathrm{EJ}$ in 2010 to over $100 \mathrm{EJ}$ in 2100, mainly due to the increased demand for high value chemicals such as ethylene. Carbon emissions increase disproportionately (from 160

Received 6th August 2013

Accepted 5th November 2013 MtC per year in 2010 to over 650 MtC per year in 2100) due to greater use of coal, especially in ammonia and methanol production. If biomass is used, it can supply a large portion of the required primary energy and reduce carbon emissions by up to $20 \%$ in 2100 compared to the reference development. Climate

DOI: $10.1039 / c 3 e e 42667 j$

www.rsc.org/ees policy can further reduce emissions by over $30 \%$. Post-consumer waste management options such as recycling or incineration with energy recovery do not necessarily reduce energy demand or carbon emissions.

\begin{abstract}
Broader context
Due to the fears associated with the growth in greenhouse gas emissions, there is an increasing interest in understanding how these emissions are related to fossil fuel use and the mitigation possibilities. Most assessments focus on reducing the combustion of these fuels in the energy system. However little attention has been paid to the possibility to reduce emissions from the non-energetic use of fossil fuels, i.e. use as feedstocks for the production of chemicals. Feedstocks account for $10 \%$ of the total primary energy supply, and $7 \%$ of global $\mathrm{CO}_{2}$ emissions and these are set to increase with rising global affluence. Analysis of this sector is complicated by the multiple material flows of these processes as well as the difficulty in assessing the supply and demand of different feedstocks. Yet it is important to understand how the fuel demand of this sector and its emissions may develop and assess different possibilities for reducing energy demand and emissions. Such possibilities include the use of bio-based polymers, climate policy and material efficiency measures such as recycling and waste incineration. We developed a simulation model highlighting key issues and evaluated different possibilities of reducing energy demand and emissions of this sector.
\end{abstract}

\section{Introduction}

In the analysis of mitigation strategies, much attention is currently paid to the anthropogenic carbon dioxide $\left(\mathrm{CO}_{2}\right)$ emissions associated with the use of fossil fuels for energy purposes. Still, around $10 \%$ of the total primary fossil energy supplied worldwide is used for non-energy purposes. Non-energy use of energy carriers is defined as "fuels that are used as raw materials [...] and are not

${ }^{a}$ Copernicus Institute of Sustainable Development, Utrecht University, Heidelberglaan 2, 3584 CS Utrecht, The Netherlands. E-mail:v.daioglou@uu.nl; Fax: +30 253 5392; Tel: +302535392

${ }^{b}$ Netherlands Environmental Assessment Agency (PBL), PO Box 1, 3720 BA Bilthoven, The Netherlands

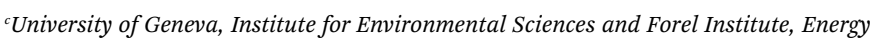
Group, Route de Drize 7, 1227 Carouge/Geneva, Switzerland.E-mail: martin.patel@ unige.ch

$\dagger$ Formerly with Copernicus Institute for Sustainable Development, Utrecht University, The Netherlands. consumed as a fuel or transformed into another fuel". ${ }^{1}$ Main uses include (i) feedstock for the production of chemicals such as ethylene, methanol and ammonia in the chemical and petrochemical sector and (ii) coke oven and oil refinery products such as waxes, lubricants, aromatics and bitumen in the energy transformation sector. The share of non-energy use relative to total energy requirements has been increasing ${ }^{2}$ and, on a global scale, non-energy usage is responsible for up to $7 \%$ of global $\mathrm{CO}_{2}$ emissions and $15 \%$ of industrial emissions. ${ }^{3,4}$

By far, the main energy carrier used for non-energy purposes is oil ( $75 \%$ globally, $>90 \%$ in the OECD countries). However, also coal and gas are increasingly being used. ${ }^{2,5}$ An option to reduce the fossil fuel use for non-energy purposes, and the related $\mathrm{CO}_{2}$ emissions, is fuel switching (including renewable feedstocks). Recent advances in technology have allowed biomass-based routes to substitute production processes starting from fossil fuels via the production of bio-based ethylene, methanol and ammonia next to other widely used compounds as well as novel chemicals that may 
replace fossil-based chemicals. ${ }^{6-9}$ The recent Special Report on Renewable Energy Sources of the Intergovernmental Panel on Climate Change (IPCC) highlighted the lack of global studies focusing on the emission reduction potential of biomass for such industrial processes. ${ }^{10}$ Further possibilities to reduce the energy demand and emissions are increasing the efficiency of material use $^{\mathbf{1 1}}$ or recycling of chemicals and energy cascading where embedded energy in non-energy products can be retrieved., ${ }^{6,12-14}$

In order to assess the potential to reduce non-energy emissions, projections of the non-energy demand and feedstock use are needed. Unfortunately, most current projections of global non-energy use are based on aggregate and opaque model descriptions. ${ }^{15-18}$ These studies, therefore, provide little insight into the potential to reduce emissions. Complications in assessing this sector arise due to complex material flows, numerous products and different end products being the raw material for other production processes. ${ }^{\mathbf{1 1 , 1 9 , 2 0}}$ Difficulties also arise because of ambiguities in non-energy data sets and uncertainties concerning emission accounting.

This study presents a global model (Non-Energy Demand and Emissions model, NEDE) in which the final demand of the nonenergy sector is disaggregated over several key products. Feedstock substitution is determined by the associated costs for the final product. The energy and mass flows of representative nonenergy processes are calibrated across a consistent global database. The future projections of the non-energy products are driven by exogenous economic, population and fuel price developments. The model is used in order to investigate the emission reduction possibilities of the non-energy sector via substitution (in particular the use of bio-based feedstocks), climate policy and increased material use efficiency (including recycling and incineration with energy recovery from post-consumer waste). The model is designed as a part of the IMAGE/TIMER integrated assessment model which provides a description of global environmental change, including the use and production of bioenergy. ${ }^{21-24}$

The paper is structured as follows. Section 2 gives an overview of the non-energy use and introduces the data set used to construct the model. Furthermore, a comparison between the data set and the IEA energy balances is provided. Section 3 introduces the model outlining the demand functions, processes involved, substitution dynamics as well as the method used to account emissions. Also a description of the scenarios projected with the model is given. Section 4 presents the primary non-energy demand and emission projections for the scenarios. Section 5 offers a discussion on the model's sensitivities and uncertainties. Section 6 summarizes the results and draws conclusions.

\section{Non-energy use}

\subsection{Overview}

Primary energy can either be used as a feedstock (i.e. converted to a product in which it is embodied) or as process energy (i.e. consumed in the conversion process). Net energy use for nonenergy purposes is the primary energy used as a feedstock without the required process energy. Gross energy for non-energy purposes is the total (feedstock + process) primary energy used to produce final products of the non-energy sector. Throughout this paper, unless otherwise stated, the term non-energy use is synonymous with gross energy use. The products of the non-energy sector are used as materials and therefore, the output is mostly quantified in mass terms (tonnes). Since this paper deals with the integration of non-energy use in an energy model (TIMER) we choose to express the production volumes of final products and the raw material inputs in energy terms, i.e. gigajoule (GJ) primary, final, feedstock or process. Primary energy is converted to final products at a given conversion efficiency $\left(\mathrm{GJ}_{\text {Final }} / \mathrm{GJ}_{\text {Prim }}\right)$. The primary energy carriers included in this study are: coal, oil, natural gas, and biomass. Electricity can be used for process energy.

In the model, the final products of non-energy have been aggregated into four distinct classes (products) whose definitions are broad enough to capture the diversity of non-energy uses while maintaining a simplified representation.:

- Steam cracking. This process produces the building blocks of the organic petrochemical industry, namely ethylene, propylene, butadiene and aromatics (benzene, toluene and xylene). In this paper these products are referred to as High Value Chemicals (HVC) according to the definition in Ren et al. ${ }^{25}$

- Ammonia production. Ammonia is used as the raw material for fertilizer production (90\%) or a feedstock for further chemical production (10\%). ${ }^{26}$ Ammonia is produced by the Haber-Bosch process where hydrogen is reacted with nitrogen at a high pressure over a catalyst. Hydrogen can be derived from natural gas or oil (via steam reforming), coal or biomass (gasification). Currently, natural gas is used as the main feedstock in most countries with the exception of China, which uses significant amounts of coal. ${ }^{\mathbf{1 4}}$

- Methanol production. Methanol is primarily used for the production of various chemicals (e.g. formaldehyde) or it is used directly as a solvent. ${ }^{27}$ Syngas produced from natural gas, petroleum products or coal is reacted with hydrogen over a catalyst to produce methanol. ${ }^{28}$

- Refinery products. These are the heavier refinery products obtained from the distillation of crude oil and consumed for non-energy purposes. The main products are lubricants, aromatics (BTX - benzene, toluene, xylene) and bitumen.

\subsection{Historic non-energy use}

We have assessed the historical non-energy use for the above products for each of the 26 regions of the IMAGE/TIMER model. ${ }^{29}$ Non-energy use of each product is estimated as the product of production volumes and so-called specific non-energy use.§ Production capacities of steam cracking and refinery products are available from the Oil Gas J., ammonia from the US Geological Survey and methanol from the Methanol Institute. ${ }^{30-33}$ Production volumes are subsequently estimated by assuming a capacity

$\ddagger$ Non-energy products, which are not accounted for are soda ash, anodes for aluminium production, carbon black and carbides. They account for a minor part of non-energy use $(<5 \%){ }^{14}$

$\S$ Specific non-energy consumption is defined as the factory gate-to-factory gate final energy use required to produce one unit (e.g., one tonne or GJ) of the chemical. It excludes the energy use of processes outside the chemical production processes such as mining and extraction of fuels. For steam cracking, it excludes backflows to refineries. 
utilization rate of $90 \% .^{20}$ As mentioned above we used the gross non-energy which includes the related process energy used for the production of these products. We chose to do so due to limitations in the IEA data. The IEA questionnaires request all countries to report their non-energy use based on the net definition of the non-energy use, but studies have shown that most countries do not report their non-energy use by following these questionnaires. ${ }^{19,20}$ Specific non-energy use and process energy use data are from the study by Weiss et $a .^{20}$ and they refer to the global average situation in 2000 .

Fig. 1 shows the energy use of the non-energy sector estimated according to the bottom-up methodology described above (aggregating the contribution by product) for some key regions as well as at a global level. Also shown is the total net non-energy use as reported in IEA energy statistics. ${ }^{34}$ Globally, the shares of the categories mentioned above were $41 \%, 25 \%, 5 \%$ and $28 \%$ for HVC, ammonia, methanol and refinery products, respectively, in 2007. Western Europe and the USA account for almost half of the global non-energy use (primarily for HVC and refinery products). However, their total volume has not increased during the investigated period. In other regions, where growth rates are significant, ammonia and methanol production take a larger share of the non-energy use. A discrepancy between the bottom-up data and the IEA non-energy estimates for total non-energy use is clearly visible. Though the two approaches show similar trends, the difference in the volume of non-energy use between the two approaches for the 1996-2007 period confirms the earlier findings of Weiss et al. regarding the inconsistencies in $2000 .^{20}$

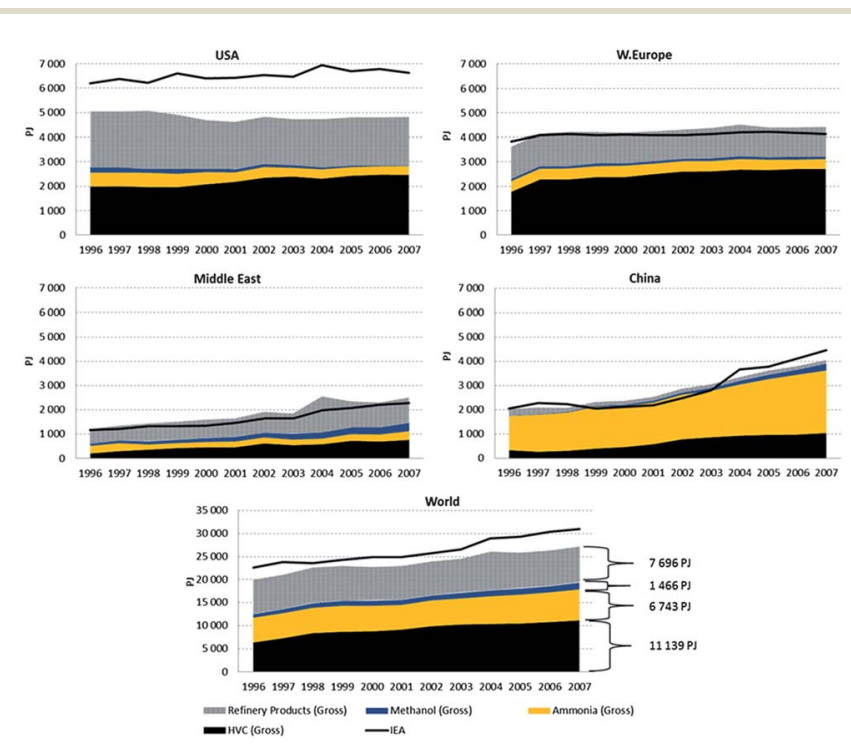

Fig. 1 Gross consumption of non-energy (PJ) for four key regions (accounting for over half of global capacity) and world total, disaggregated over 4 non-energy products. Also included is the total non-energy use as reported by the IEA.

\section{Non-energy demand and emissions (NEDE) model}

The NEDE model is a global long-term simulation model designed to get insight into trends in primary energy use for non-energy purposes up to the year 2100 and the possible mitigation strategies in this sector. The model describes the non-energy use for the 26 IMAGE/TIMER regions. The long-term focus of the model implies that it needs to aggregate detailed bottom-up data. It does so by linking the non-energy sector's energy demand to the non-energy use products outlined in Section 2.1 and representative production processes in order to maintain both relevance and functionality. An outline of the model's key steps is shown in Fig. 2.

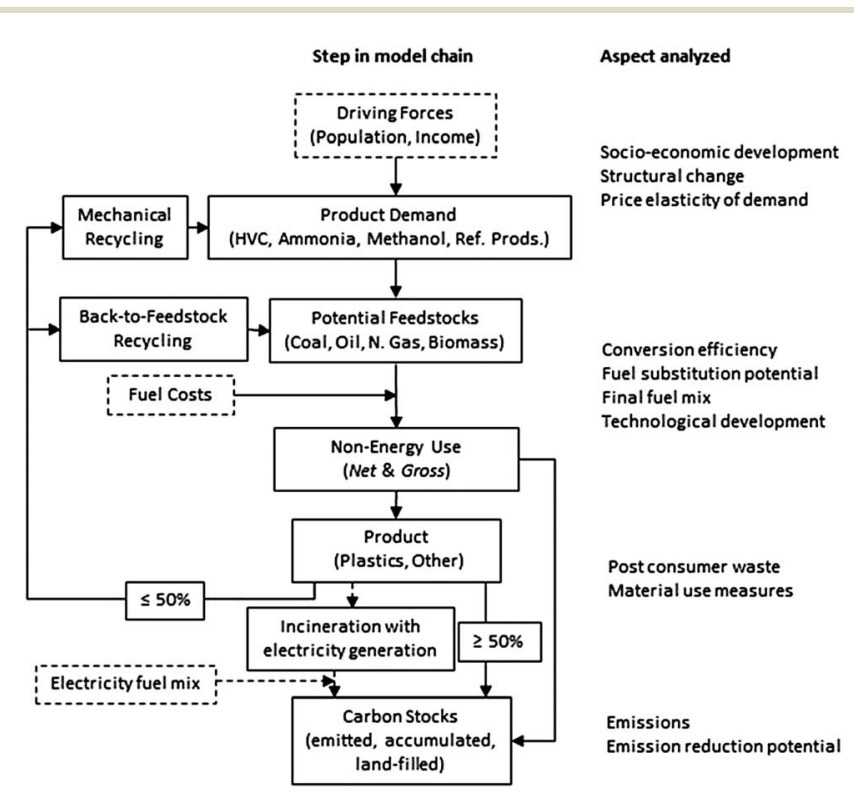

Fig. 2 Overview of the NEDE model. Explicit steps of the model indicated on the left and relevant issues indicated on the right. Dashed boxes show inputs from IMAGE/TIMER and dashed lines show optional calculations (not included as a competing option).

\subsection{Demand functions}

In the model, demand for primary energy ( $\mathrm{GJ}_{\text {Prim }}$ ) is driven by the demand for each final product (HVC, ammonia, methanol, refinery products) $\left(\mathrm{GJ}_{\mathrm{Final}}\right)$. The regional historic demand outlined in Section 2.2 was analysed in order to determine the relationship between per capita demand for each product (GJ Final per cap) and economic growth (GDP per cap). Consequently, regional non-energy intensity per product is modelled as a logistic growth relationship between $\mathrm{GJ}_{\text {Final }}$ demand per capita and GDP per capita according to eqn (1). ${ }^{35,36}$ It is important to note that the model does not include trade of final products between regions. In the NEDE model, regional historic intensity is used which converges to the global per capita demand for non-energy products by 2050 . The regional data and 'global' best-fit relationship are shown in Fig. 3.

$$
\text { Intensity }_{\mathrm{R}, \mathrm{P}}=\left(\alpha_{\mathrm{P}} \mathrm{e}^{-\frac{\beta_{\mathrm{P}}}{\mathrm{GDP}_{\mathrm{R}}}}\right) \times \min _{1}\left(\gamma_{\mathrm{P}}^{\left(\mathrm{GDP}_{\mathrm{R}}-20000\right)}\right)
$$

where: intensity $=\mathrm{GJ}_{\text {Final }}$ per cap demand of each non-energy product; GDP = exogenous projection of per capita GDP, in real 2005 US dollars $\left(\$_{2005}\right.$ per cap); $\alpha, \beta, \gamma=$ constants per product. 


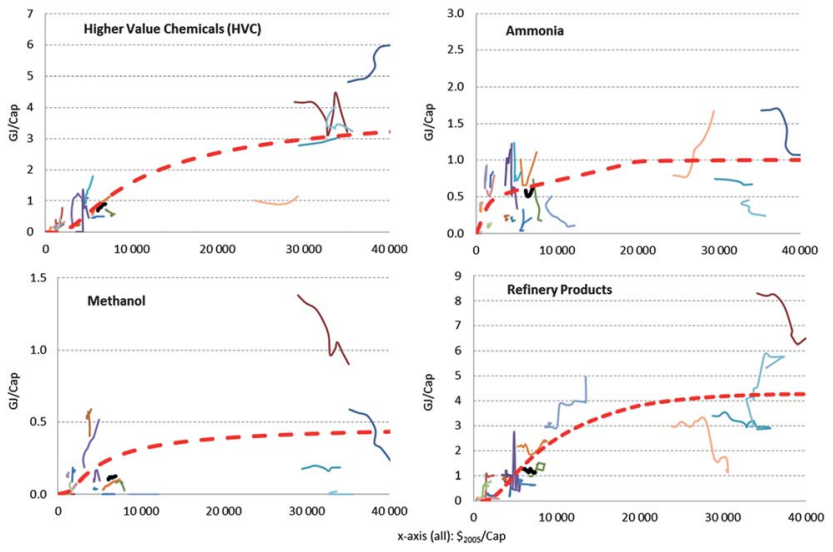

Fig. 3 Intensity of demand for non-energy products, $G J_{\text {Final }}$ per cap vs. GDP\$2005 per cap. 1996-2007 IMAGE/TIMER region data (thin lines) and NEDE formulation (dashed red line).

Table 1 Coefficients used in calculating intensity of demand of each non-energy product

\begin{tabular}{lllll}
\hline & Steam cracking & Ammonia & Methanol & $\begin{array}{l}\text { Refinery } \\
\text { products }\end{array}$ \\
\hline$\alpha$ & 4.08 & 1.02 & 0.48 & 5.86 \\
$\beta$ & 9457 & 679 & 4330 & 8525 \\
$\gamma$ & 1 & 1.028 & 1 & 0.995 \\
$R^{2}$ & 0.78 & 0.39 & 0.20 & 0.75 \\
\hline
\end{tabular}

The subscripts $\mathrm{R}$ and $\mathrm{P}$ refer to regions and non-energy products respectively. All coefficients and respective regression coefficients are listed in Table 1.

We assume that the final demand is also sensitive to increases in energy prices by introducing a price elasticity of demand (PED). ${ }^{37,38}$ This simulates decreases in demand (either by behavioural changes or increased efficiency measures) with increasing energy prices. Thus, final demand (in $\mathrm{GJ}_{\text {Final }}$ ) is driven by the economic growth, population as well as price of energy carriers:

$$
\text { final demand }_{\mathrm{R}, \mathrm{P}}=\text { intensity }_{\mathrm{R}, \mathrm{P}} \times \text { population }_{\mathrm{R}} \times \mathrm{PED}_{\mathrm{R}}
$$

This final demand can be met by a supply (of gross primary energy) of coal, oil, natural gas or biomass. Primary energy demand is calculated from the conversion efficiencies of each feedstock to final products according to representative processes (Section 3.2) as well as the market shares each process achieves (Section 3.3).

\subsection{Processes}

High value chemicals. Worldwide, the products of steam cracking (i.e. HVC) represent the largest share of the non-energy sector and also offer a substantial potential for emission reduction. ${ }^{39}$ The representation of this product group is therefore relatively detailed in NEDE. Primary fuels are converted to intermediates (e.g. naphtha, ethanol), which are in turn converted to HVC. The routes to HVC from primary fuels included in the NEDE model are shown in Fig. 4. Each step (primary-to- intermediate and intermediate-to-product) has its own conversion efficiency, cost (capital and operation and maintenance (O\&M)) and energy requirement based on an analysis of possible petrochemical production processes. ${ }^{25,39,40}$ Fig. 4 also show the potential recycling options for post-consumer wastes of synthetic organic products as described below.

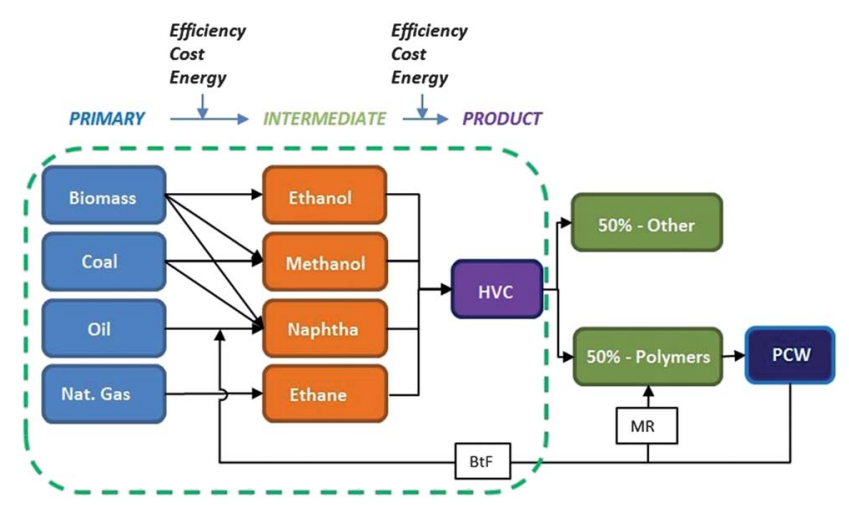

Fig. 4 Material flows for the production of HVCs. Also shown is the downstream production of HVC post-consumer waste and recycling possibilities (described below).

The technical data used for the various potential HVC processes, as well as assumed potential future improvements, are shown in Table 2. Most of the data have been taken from Ren et $a l^{9,25}$ while for the production of first and second generation biofuels data come from more recent databases. ${ }^{\mathbf{4 0 , 4 1}}$ The variable costs due to energy requirement (total of feedstock energy and process energy) depend on the cost projection of the relevant energy carriers. In some cases the production of HVC also includes net co-production of electricity which may act as a source of revenue. All energy costs or revenues from coproduced electricity depend on the projections of the price of the relevant energy carrier according to the IMAGE/TIMER model.

Ammonia. In ammonia production, natural gas is currently the main feedstock but also other feedstocks (coal, oil, gas and lignocellulosic biomass) can be used. We have introduced these alternative fuels on the basis of an "energy ratio" compared to natural gas, indicating how much of the primary fuel would be required to replace $1 \mathrm{GJ}$ of natural gas for the production of ammonia. The gross energy requirement for ammonia production from fossil fuels is taken from Neelis et al. ${ }^{\mathbf{4 3}}$ while for lignocellulosic biomass, the relative efficiency of hydrogen production from biomass compared to natural gas is used. ${ }^{\mathbf{4 4}}$ The energy ratios of coal, oil and biomass are 1.47, 1.21 and 1.50 $\mathrm{GJ}_{\text {Prim }} / \mathrm{GJ}_{\text {NGas-eq }}$, respectively.

Methanol. The efficiencies of methanol production from fossil fuels are derived from Neelis et $a .^{43}$ and those for the production from lignocellulosic biomass from Gerssen-Gondelach et al. ${ }^{40}$ The efficiencies for coal, oil, natural gas and biomass are $0.52,0.52,0.63$ and $0.60 \mathrm{GJ}_{\text {Methanol }} / \mathrm{GJ}_{\text {Prim }}$ respectively.

Refinery products. Refinery products are a diverse set of chemicals including aromatics, bitumen and lubricants, which 
Table 2 Technical and cost parameters used for each HVC production route. Future (2050) values are shown in brackets. Conversion efficiencies for production of intermediate and final HVC are shown

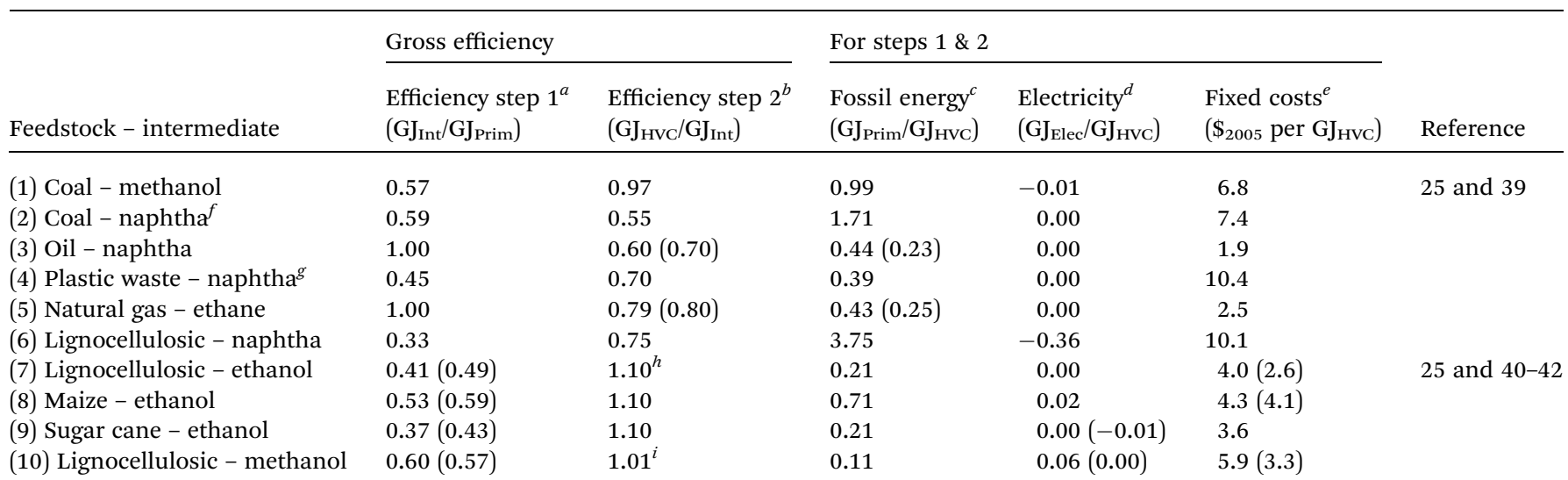

${ }^{a}$ Conversion efficiency of primary fuels to intermediate products for specific route. Routes 1-6 based on lower heating values (LHVs). Routes 7-10 based on higher heating values (HHVs). Other possible products of each route are ignored. Future values based on the current best available technology. Routes 3 and 5 have a $1^{\text {st }}$ step efficiency of 1 since the intermediate is a necessary product of oil or gas distillation respectively. ${ }^{b}$ Conversion efficiency of the route intermediate to HVC. All conversions based on LHV. For routes 1-6 LHV $\mathrm{HVC}=45 \mathrm{GJ} \mathrm{t}^{-1}$. For routes 7 to 10 it is assumed that the HVC is ethylene, and thus $\mathrm{LHV}_{\mathrm{HVC}}=47 \mathrm{GJ} \mathrm{t}^{-1}$. For routes 7 to 10 see relevant footnotes. ${ }^{c}$ Does not include feedstock energy for the HVC. In the case of multiple products, energy use is allocated on the basis of their economic values as in Ren et al. (2006) and Ren et al. (2009). ${ }^{d}$ Electricity requirement for conversion of primary fuels to HVC. In case there is a net production of electricity, the value is negative. ${ }^{e}$ Includes annualized capital costs and O\&M costs for steps $1 \& 2$. A capital recovery factor of $13 \%$ and a capacity utilization rate of $90 \%$ are assumed. Biomass processes have significant cost reductions due to learning-by-doing in the production of the intermediates according to projections of the IMAGE/TIMER model (Bio case, see Section 3.5). ${ }^{f}$ This route is the liquefaction of coal to produce naphtha. Fischer-Tropsch naphtha via coal gasification is ignored due to extensive energy and gas cleanup needs. ${ }^{g}$ BASF process. Naphtha production from polyolefins via liquefaction, pyrolysis and separation, also called Back-to-Feedstock (BtF) recycling in this paper. ${ }^{h}$ For routes $7-9$, mass yield is $0.61 t_{H V C}$ per $t_{\mathrm{Ethanol}}$ and $\mathrm{LHV}_{\mathrm{Ethanol}}=26 \mathrm{GJ} \mathrm{t}{ }^{-1}$. Energetic efficiency is greater than 1 (routes 7-10) due to endothermicity with energy derived from fossil energy requirement (column 4). ${ }^{i}$ Mass yield is $0.43 \mathrm{t}_{\mathrm{HVC}}$ per $\mathrm{t}_{\text {Methanol }}$ and $\mathrm{LHV}_{\mathrm{Methanol}}=20 \mathrm{GJ} \mathrm{t}^{-1}(\mathrm{Ren}, 2009)$.

remain after atmospheric distillation of oil. Substituting the feedstock (currently oil) with other energy carriers is not easy since the chemical properties of the product may vary. Other feedstocks (especially biomass) may produce products with a higher added value (such as terephthalic acid, derived from para-xylene), which may also perform the functions provided by refinery products. Due to the complexities involved in substituting refinery products with their possible replacements and the significant uncertainties which arise, they are treated in a very aggregate manner.

We assume that under all circumstances oil retains $30 \%$ of the refinery products market share since it is unlikely that bitumen (asphalt) will be produced from other feedstocks. We make this assumption for a number of reasons. Bitumen is an unavoidable product of the refining industry, and, as petroleum sources increasingly move towards heavy oil, the availability of bitumen will increase. Furthermore, it is most likely that biomass would be used for products with higher added value and so bio-based asphalt is unlikely. Coal, natural gas and biomass compete with oil for the remaining market share $(70 \%)$. This competition is based on the relative price of refinery products from coal, natural gas and biomass to the price of equivalent products from oil (price ratio). In the initial conditions of the model, the price ratio of coal, natural gas and biomass is set to three. During the simulation period (starting in 2007), the price ratio for coal and natural gas decreases as the relative price of oil increases. For biomass it is assumed that it approaches unity by 2050 since it is already observed in Europe that bio-based lubricants are dynamically entering the market. ${ }^{45}$

Post-consumer plastic waste. In order to assess possibilities of material efficiency improvement throughout the lifecycle of non-energy products (such as recycling and incineration with electricity generation), we also account for possible routes for post-consumer plastic waste (PCW). PCW represents the total amount of plastics which have reached the end of their lifetimes. The availability of PCW is determined by assuming that a certain fraction of the downstream products of HVC, methanol and refinery products of the previous year are available as PCW, while the rest is considered accumulated in plastics or used for non-plastic products. More specifically, $50 \%$ of HVC, $20 \%$ of methanol and $30 \%$ of refinery products become plastics. ${ }^{4-47}$ It is assumed that $50 \%$ of the plastic produced can be recycled since not all plastics can be collected as PCW. In this study, PCW can contribute to HVC production after being processed in two different recycling processes, namely mechanical recycling (MR) or Back-to-Feedstock recycling (BtF). The MR route reduces the demand for HVC, while BtF acts as an alternative route for HVC production (as shown in Fig. 4). ${ }^{6,13,48,49}$

It is assumed that the price of PCW is $\$ 4.4$ per GJ in 2010 representing the US and Western Europe. ${ }^{9}$ The future price of PCW is linked to the price of fossil fuels. The volume of PCW undergoing MR is capped at $30 \%$ in order to account for decreased material properties (downcycling). ${ }^{13,45-47}$ It is assumed that this process requires $0.7 \mathrm{GJ}$ of fossil-based heat 
and $0.7 \mathrm{GJ}$ of electricity for the production of $1 \mathrm{GJ}$ of HVC equivalent. ${ }^{50}$ The remaining PCW can undergo the BtF process (see Plastic waste naphtha in Table 2). Both recycling routes compete for a market share of HVC production with other production routes.

In addition to recycling processes, PCW incineration with energy recovery can also contribute to emission reduction relative to electricity generation from separate power plants (Section 3.5). ${ }^{48}$ This option is also included in our model, but we exclude any competition with the two recycling options. Thermal efficiency of waste-to-electricity is set at $30 \%$ with a future projection to $40 \%$. This assumes that power plants are optimised for waste electricity generation. ${ }^{51,52}$ Electric efficiency and emission factors of the displaced electricity generation are taken from the baseline of the IMAGE/TIMER model.

\subsection{Fuel allocation}

Allocation of primary energy carriers to each production process depends on the competitiveness of each carrier in producing the final product. Each possible route competes based on their relative costs according to a multinomial logit function shown in eqn (3). This function allows modeling of market heterogeneity by assigning the largest market share to the cheapest route, with the remaining market share being shared amongst the other routes based on their relative costs.

$$
\mathrm{MS}_{\mathrm{R}, \mathrm{P}, \mathrm{EC}}=\frac{\mathrm{e}^{-\lambda c_{\mathrm{R}, \mathrm{P}, \mathrm{EC}}}}{\sum_{\mathrm{EC}} \mathrm{e}^{-\lambda c_{\mathrm{R}, \mathrm{P}, \mathrm{EC}}}}
$$

where MS is the market share each feedstock gets for each product, $c$ is the cost of each product per primary fuel and $\lambda$ is the logit parameter which acts as the elasticity between relative prices. The subscripts R, P and EC stand for region, product and energy carrier, respectively. As shown in eqn (4), cost depends on the price of the energy carrier as well as its conversion efficiency, the annualised fixed costs and any potential taxes on the carbon content of fuels (in the scenario where climate policies are accounted for, see Section 3.5). Fixed and variable costs are only included for HVC production since data for all of the other production routes are scarce and fuel prices are the main cost component. ${ }^{53}$ The fuel price is measured in $\$_{2005}$ per $\mathrm{GJ}_{\text {Prim }}$ and the efficiency of conversion (Eff) $\uparrow$ is $\mathrm{GJ}_{\text {Final }} / \mathrm{GJ}_{\text {Prim }}$. Thus the cost is measured in $\$_{2005}$ per $\mathrm{GJ}_{\text {Final }}$.

$$
\begin{aligned}
\operatorname{Cost}_{\mathrm{R}, \mathrm{P}, \mathrm{EC}}= & \frac{\text { fuel price }_{\mathrm{R}, \mathrm{P}, \mathrm{EC}}+\mathrm{C} \operatorname{tax}_{\mathrm{EC}}}{\mathrm{Eff}_{\mathrm{P}, \mathrm{EC}}}+\text { fixed costs } \\
& + \text { variable costs } \mathrm{P}_{\mathrm{P}, \mathrm{EC}}
\end{aligned}
$$

\subsection{Emission accounting}

The model tracks the carbon flows from the primary energy carrier to the final product, as well as emissions from heat

9 For the refinery products, "Eff" is the inverse of the "price ratio" and for ammonia it is the inverse of the "energy ratio" (described in the respective parts of Section 3.2). production required for the conversion process. Only $\mathrm{CO}_{2}$ emissions are accounted, while potential methane emissions, which may be important in HVC and methanol production, are ignored due to lack of data. The accounting of the emissions is in line with the 'Good Practice' methods outlined by the IPCC guidelines for emission inventories. ${ }^{54}$ All emissions are measured in MtC.

- HVC production. The model simulates the flow of both process and feedstock energy carriers. Consequently the carbon content of the fuel combusted during the production process is included in the emissions. This includes emissions from any electricity use. The carbon content of the feedstock fuels is assumed indefinitely accumulated (sequestered) unless it is incinerated for energy recovery (see postconsumer waste in Section 3.2). This is in line with the IPCC good practice guidelines for the tier 2 emission accounting method.

- Ammonia. As fossil fuels are required for hydrogen used for the production of ammonia, all of the carbon is emitted as $\mathrm{CO}_{2}$. Downstream urea production which would reduce these emissions is ignored due to lack of global urea production data and projections and because a substantial share of the global urea production is used as fertilizer which releases $\mathrm{CO}_{2}$ when decomposing. This is in line with the IPCC good practice guidelines for the tier 1 emission accounting method.

- Methanol. Emission factors for methanol production from different feedstocks are taken from Neelis et al. ${ }^{\mathbf{4 3}}$ These factors assume emissions due to fuel combustion while the carbon embedded in the final product is assumed sequestered and are in line with IPCC tier 1 emission factors.

- Refinery products. Most refinery products end up as materials that are used for a long term such as bitumen or aromatics, which are assumed to sequester their embedded carbon. About $10 \%$ of refinery products are lubricants of which $20 \%$ are oxidised during use (ODU) according to the IPCC tier 1 emissions accounting method.

Carbon not emitted according to the above rules is assumed to be accumulated in the products. Thus, PCW has a certain carbon content, which is conserved in HVC if recycled and emitted if incinerated for electricity production. Further simplifying assumptions are made in order to keep the modelling manageable: many derivatives of the HVCs (particularly ethylene derivatives) may emit $\mathrm{CO}_{2}$ in the form of ODU. ${ }^{55}$ Knowledge of specific flows of chemicals and uses per region would be required in order to properly assess this. Since our analysis is on global and long term scales, it is too uncertain to make such assumptions and therefore most ODU emissions are ignored. An emission factor is attached to biomass production (5-7 kg C per $\mathrm{GJ}_{\text {Prim }}$, varies across regions) which accounts for the non-renewable energy use during production as well as net emissions due to the displacement of natural vegetation. This is in agreement with the estimates of the International Food Policy Research Institute (IFPRI). ${ }^{56}$ The carbon content of biomass itself is zero since it is assumed to come from sustainably grown renewable resources (plantations and residues). 
Table 3 Key indicators (global average) of the OECD Environmental Outlook baseline

\begin{tabular}{|c|c|c|c|c|c|}
\hline Year & $\begin{array}{l}\text { GDP per cap } \\
(\$ 2005 \text { per cap })\end{array}$ & $\begin{array}{l}\text { Price of oil } \\
\left(\$_{2005} \text { per } \mathrm{GJ}_{\text {Prim }}\right)\end{array}$ & $\begin{array}{l}\text { Price of coal } \\
\left(\$_{2005} \text { per } \mathrm{GJ}_{\text {Prim }}\right)\end{array}$ & $\begin{array}{l}\text { Price of gas } \\
\left(\$_{2005} \text { per } \mathrm{GJ}_{\text {Prim }}\right)\end{array}$ & $\begin{array}{l}\text { Price of biomass } \\
\left(\$_{2005} \text { per } \mathrm{GJ}_{\text {Prim }}\right)\end{array}$ \\
\hline 2010 & 7148 & 8.3 & 2.7 & 3.5 & 6.0 \\
\hline 2020 & 9155 & 9.5 & 2.4 & 4.0 & 6.0 \\
\hline 2030 & 11738 & 10.5 & 2.6 & 5.6 & 6.1 \\
\hline 2040 & 15159 & 12.1 & 2.6 & 7.0 & 7.0 \\
\hline 2050 & 19360 & 13.8 & 2.6 & 7.5 & 7.1 \\
\hline 2060 & 24653 & 15.7 & 2.5 & 8.4 & 8.2 \\
\hline 2070 & 31096 & 18.7 & 2.5 & 8.7 & 8.3 \\
\hline 2080 & 38912 & 22.8 & 2.5 & 9.5 & 9.1 \\
\hline 2090 & 47968 & 25.7 & 2.5 & 11.0 & 9.6 \\
\hline 2100 & 58058 & 26.8 & 2.5 & 11.9 & 9.6 \\
\hline
\end{tabular}

\subsection{Scenarios}

In this study, we apply different scenarios to assess the effects on energy use and emission reduction potential by biomass, climate policy and PCW policies. In all cases, the population, GDP and energy prices are based on the OECD Environmental Outlook. ${ }^{57}$ Exogenous global GDP and population growth, as well as energy carrier prices as projected by the IMAGE/TIMER model are shown in Table 3. The prices of energy carriers are governed by resource depletion dynamics (price increases) and learning by doing in technology conversion (price decreases).

A baseline projection is made in order to determine the future demand of non-energy products. This final demand is then met by primary energy carriers whose market shares are based on eqn (3). We simulate two separate cases for the baseline projections: (1) non-energy products are produced from fossil fuel energy carriers only, and (2) in addition to fossil fuels, biomass can also be used as a feedstock, competing with fossil fuels. By doing so, we assess the total emissions, demand for primary energy carriers and the mitigating effect of the use of biomass. These two cases will be referred to as the NoBio and Bio cases respectively.

Climate policy scenarios. Climate policy scenarios are performed for the two base cases. Carbon taxes of \$20, \$50 and $\$ 100$ per $\mathrm{t} \mathrm{C}$ are applied to the price of primary fossil fuels in order to determine how sensitive the energy mix (and associated emissions) of non-energy use is to energy prices and how the availability of biomass affects the fuel substitution possibilities. It is assumed that the tax is applied in 2015 globally and remains constant throughout the simulation period.

Finally, two PCW policy scenarios are developed in order to investigate the effects of (1) increased recycling rates and, (2) incineration with electricity generation. In the first case, the full potential of PCW available for either MR or BtF recycling is used (something which does not happen in the base cases where it competes with other options). In the second scenario, PCW can be used by the power production sector replacing the projected use of fossil-based fuels in the baseline\|. Regional

|| The European Union (EU) currently incinerates $20 \%$ of its PCW. ${ }^{48}$ This is ignored in our base cases since the effects of different routes are assessed, not the 'business as usual'. demand for electricity and fuel use is based on projections of the IMAGE/TIMER model for the OECD Environmental Outlook scenario. The carbon content of the PCW is assumed emitted, and the total power sector emissions are compared with the baseline emissions. These two scenarios are called the full recycle and incineration scenarios respectively.

\section{Results}

The following sections outline the projections of the NEDE model for future demand for non-energy uses and its associated emissions under the different scenarios described in Section 3.5. Detailed numerical results concerning primary energy use and carbon flows under all scenarios are available in the Appendix.

\subsection{Baseline projections}

Fig. 5 shows the projected global non-energy demand until 2100 in $\mathrm{EJ}_{\text {Final }}$ in the baseline with a breakdown by final products (left) or region (right). The respective (global) primary energy demand is shown in Table 6 in the Appendix. The final demand is identical for the NoBio and Bio cases. Total final demand increases from $19 \mathrm{EJ}$ in 2010 to $47 \mathrm{EJ}$ in 2050 and $72 \mathrm{EJ}$ in 2100 , as a consequence of volume growth for all products. The increase is asymmetric across products, with the greatest increase in demand coming from HVC and refinery products since these products have the highest intensity of demand at high incomes. Between 2010 and 2100, HVC increases its share from $30 \%$ to $38 \%$ while the share of ammonia falls from $21 \%$ to $12 \%$. The shares of methanol and refinery products are constant at $4 \%$ and $46 \%$, respectively. The growth is driven by developing economies, with Europe, North America and the Former Soviet Union (FSU) not contributing to non-energy demand growth. These regions already have high intensity levels which have been declining in the past years, and further economic growth does not increase their non-energy demand (see Fig. 3). On the other hand the Asia-Pacific, South Asia and Africa regions have both growing economies and populations, leading to a large growth in demand. 

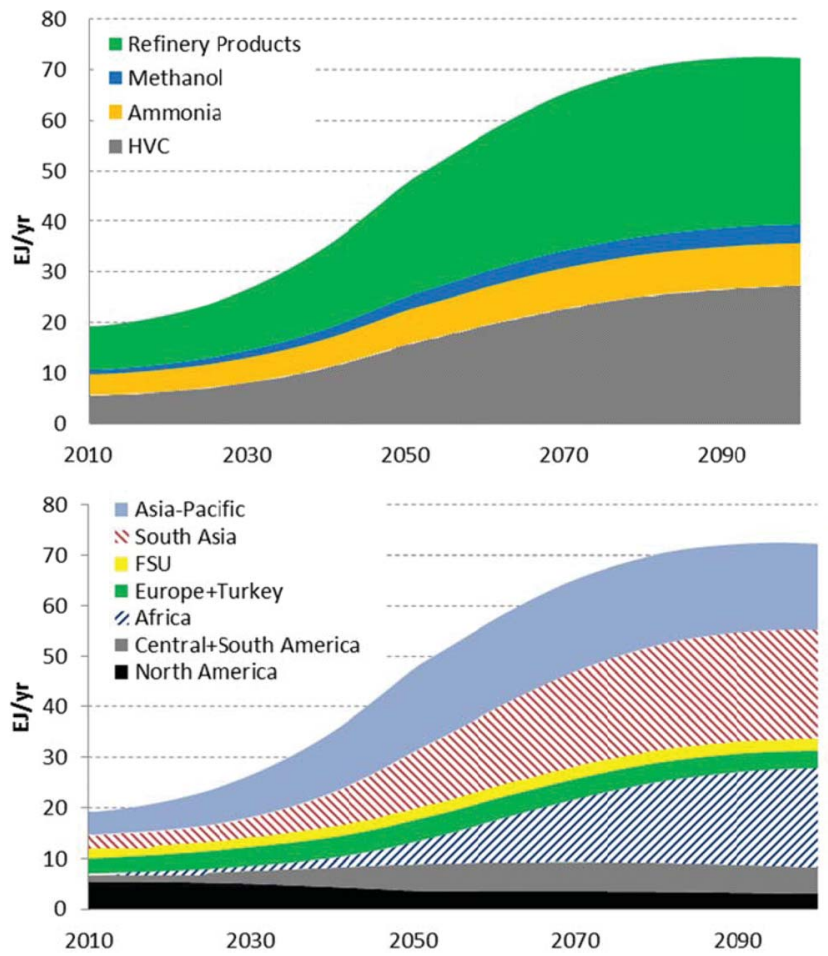

Fig. 5 Total global final non-energy demand. Per product, $E J_{\text {Product }}$ (top), per region (bottom)

It is important to consider these changes in product and regional demand when assessing substitutability of different energy carriers and thus primary energy demand and emissions. This is because different products have different fuel switching possibilities (and efficiencies) and energy costs vary across regions. Primary energy demand and emissions will be the focus of the rest of this section.

Fig. 6 shows the primary energy demand per energy carrier (including PCW) for the NoBio and Bio cases. The shares of primary energy carrier use per product are shown in Table 7 in the Appendix. One may note the rapid reduction in oil demand between 2010 and 2020. Pre-2010 the model is forced to reproduce the total fuel use reported in the IEA energy statistics while the shares of each final product are based on the data outlined in Section 2.2. The difference in the total demand between the data and IEA statistics is obvious in Fig. 1 and may come from erroneous reporting in the IEA statistics. Both the total demand and fuel use are re-adjusted to the bottom-up data between 2010 and 2020. The projections show that the global demand for primary energy carriers for non-energy use increases from approximately $30 \mathrm{EJ}$ in 2010 to $100 \mathrm{EJ}$ (and $10 \mathrm{EJ}$ of PCW, most of which is recycled via $\mathrm{MR}$ ) in 2100. This is equivalent to a compound annual growth rate of primary energy of $2 \%$ per year from 2010 to 2050 and 1.5\% per year for the entire period analysed. Gas becomes increasingly important in the short term, mainly due to fuel switching in HVC production in developed regions, while developing regions continue using oil. Natural gas is also used heavily in ammonia and methanol production. In the longer term, increases in the price of oil lead to further increase in use of natural gas and eventually shift to coal based chemistry. The increase in coal usage
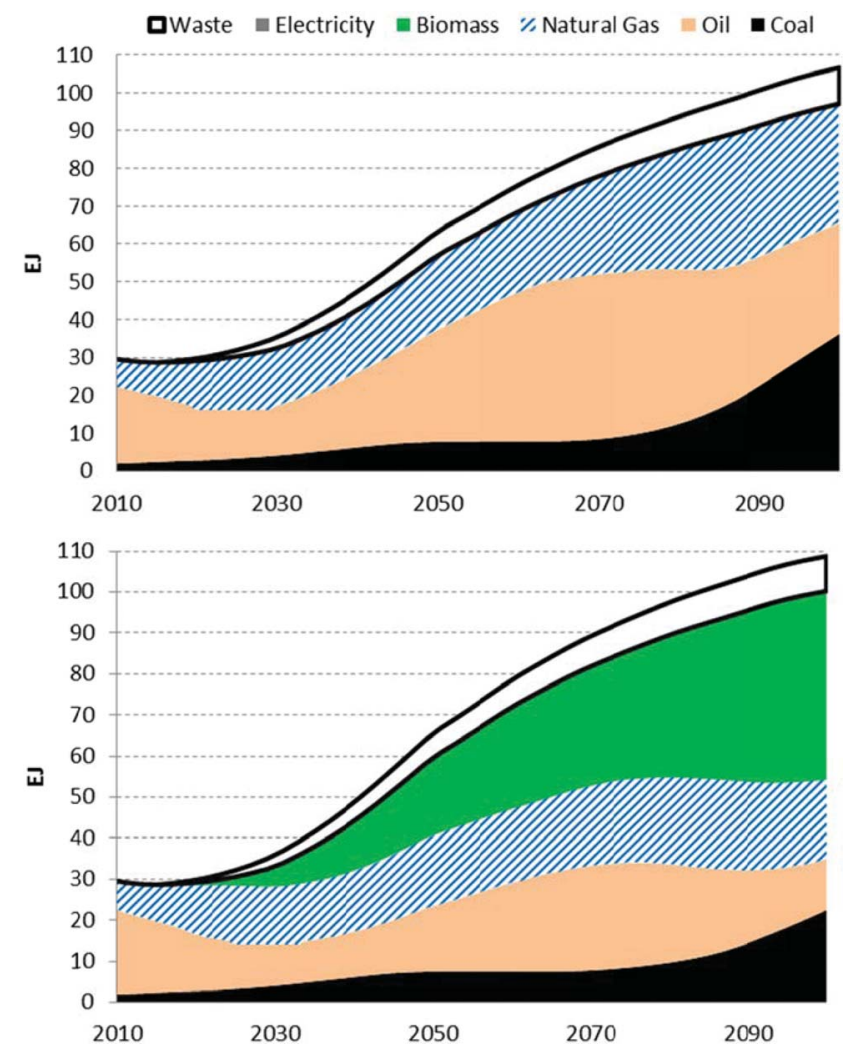

Fig. 6 Total gross primary non-energy demand (EJ) per energy carrier. NoBio (top) and Bio (bottom).

in the long term is largely due to its requirement for process heat generation associated with switching to coal-based HVC. Furthermore, coal is increasingly used for methanol and ammonia production towards the end of the century.

If biomass is also used as a feedstock (Fig. 6, right), it is projected to become a significant non-energy feedstock supplying 19 $\mathrm{EJ}$ in 2050 and $45 \mathrm{EJ}$ in 2100. Biomass becomes competitive due to disproportionate price increases in fossil fuels as well as cost reductions in biobased methanol production due to learning. By 2100 , most of the biomass (50\%) demand replaces oil which is used for the production of refinery products. $43 \%$ of the biomass is used to produce HVC, replacing all fossil fuels but primarily coal, which is the marginal fuel in the NoBio case and about $7 \%$ is used for ammonia production. Biomass accounts for $65 \%$ of refinery product, $46 \%$ of HVC and $21 \%$ of ammonia production in 2100 .

Since feedstocks for HVC account for more than a third of the non-energy use according to the projections (Table 7) and this product is the most interesting concerning renewable feedstocks and PCW recycling, it is worth looking at it in more detail. Fig. 7 shows the primary energy carriers used as feedstocks for HVC production only. The model projects that all the waste available for mechanical recycling is used, while back-to-feedstock recycling is minor. This is due to its high costs and energy requirement. Also the continued importance of oil (especially outside North America) in the medium term is shown. Biomass becomes important after 2030 due to cost reductions in HVC production from bio-based methanol. Primary energy demand, excluding waste, in 2100 increases from 30 EJ in the NoBio case to 34 EJ in 
the Bio case due to the lower conversion efficiency of biomass to HVC compared to fossil fuels.
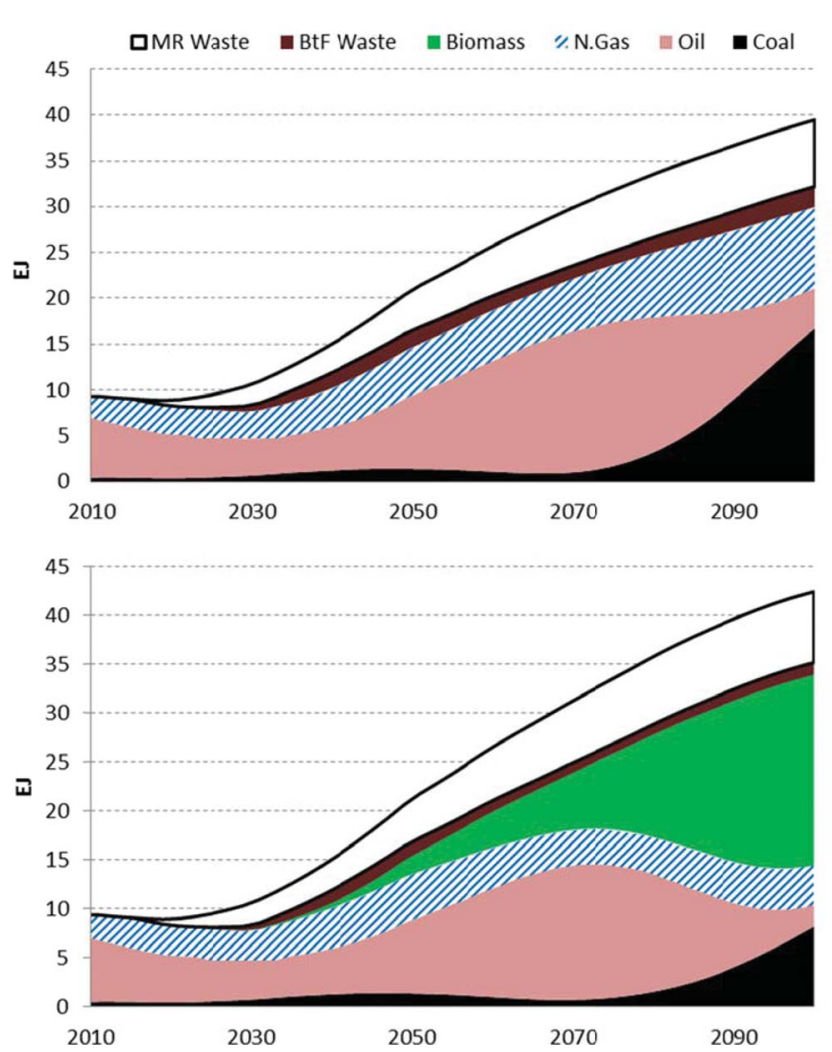

Fig. 7 Net primary energy demand (EJ) for HVC, including recycled fractions. NoBio (top) and Bio (bottom).

As the demand for non-energy products increases, emissions of this sector also increase. Fig. 8 shows, for the years 2010, 2050 and 2100 , how the global annual carbon flows broken down between emitted, accumulated and recycled are distributed. The use of biomass can overall significantly limit the total amount of carbon flows within the sector in the long run, especially the carbon accumulated in products. It can reduce annual emissions by 2100 from 677 MtC per year to $544 \mathrm{MtC}$ per year (20\% reduction) by replacing a large portion of fossil fuels by biomass in ammonia production and reduction in coalbased HVC production.

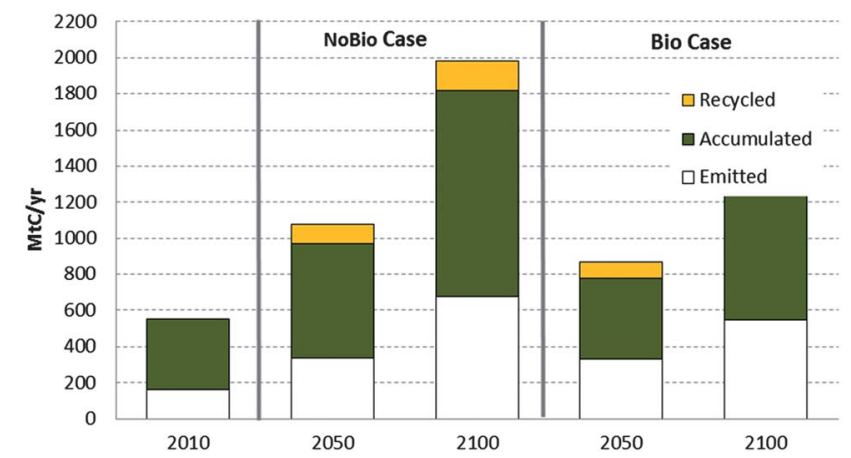

Fig. 8 Non-energy carbon flows in 2010, 2050 and 2100 for the NoBio and Bio cases.

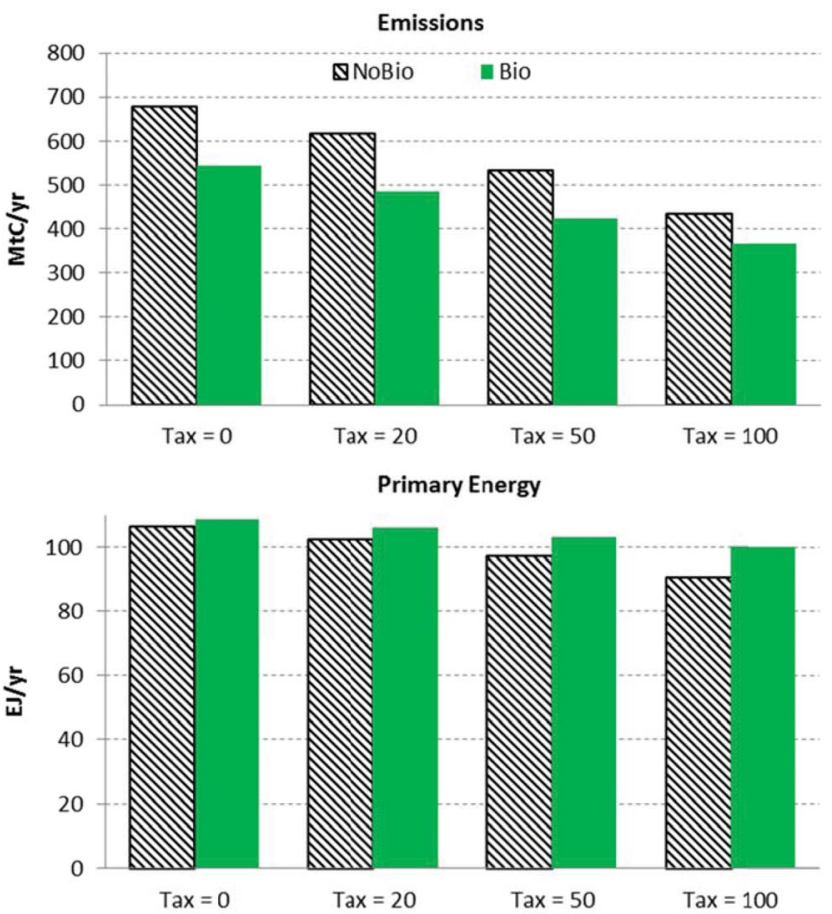

Fig. 9 Top: total emitted carbon (MtC per year), Bottom: Total nonenergy demand (EJ per year). For NoBio and Bio cases per tax level for 2100 .

\subsection{Climate policy}

In the climate policy scenarios we tax the carbon content of primary energy carriers at $\$ 20, \$ 50$ and $\$ 100$ per $t \mathrm{C}$. The effect of climate policy on total primary energy demand and the sectors' annual emissions for both NoBio and Bio cases in 2100 are shown in Fig. 9 (see Table 8 in the Appendix for the developments in fuel mix). In the NoBio case, climate policy leads to coal being replaced by natural gas and to a lesser extent oil. This reduces the energy use for coal-based HVC and lowers the overall emissions (36\% at \$100 per $\mathrm{t} \mathrm{C}$ ). In the Bio case, biomass becomes increasingly important further reducing emissions (33\% at $\$ 100$ per t C), but as previously mentioned this also reduces the conversion efficiency. Thus, climate policy has a smaller effect on primary energy demand in the Bio case than in the NoBio case. Decreases in total primary energy demand (and consequently emissions) are also driven by reduced final demand due to the price elasticity of demand.

\subsection{Post-consumer waste policies}

In the base case projections (NoBio and Bio), NEDE indicated that the waste available for mechanical recycling is utilized; back-tofeedstock recycling is not a competitive HVC production option and only used marginally. We discuss now the results of alternative PCW scenarios. The first PCW policy scenario assumes the Bio case with the BtF route forced on $70 \%$ of the PCW (the other $30 \%$ undergoing MR). The results show that forced BtF does not reduce the demand for primary energy carriers and emissions with respect to the base Bio case (Table 8 , Full recycle scenario), a conclusion that other studies have also come to. ${ }^{48}$ The reason being BtF's low efficiency and high process energy (Table 2). 
The second PCW scenario assumes that the quantity of PCW not used for recycling in the base case can be incinerated with subsequent electricity generation. This is repeated for both NoBio and Bio cases since the carbon content, and thus emitted carbon, of PCW changes. In the power sector, PCW replaces an aggregate mix of the fossil primary energy carriers, whose use in baseline projections according to the IMAGE/TIMER model is shown in Table 9 in the Appendix. Globally coal is projected to become the dominant primary fuel for electricity generation, but the carbon content (CC) of electricity decreases due to improvements in the thermodynamic efficiency of electricity generation.

Table 4 shows the primary fuel demand and carbon content per GJ fuel use of the electricity generation sector in the base case. The carbon content of electricity is $464 \mathrm{~g} \mathrm{CO}_{2}$ per $\mathrm{kW} \mathrm{h}$ and $453 \mathrm{~g} \mathrm{CO}_{2}$ per $\mathrm{kW} \mathrm{h}$ for 2050 and 2100 respectively. Also shown are the CC and volume of PCW in the NoBio and Bio cases in 2050 and 2100. It is assumed that waste-to-electricity generation efficiency is $30 \%$, increasing to $40 \%$ in $21000^{51,52}$ Efficiency of fossil based electricity generation, globally increasing from $42 \%$ to $62 \%$, is based on the projections of the IMAGE/TIMER model and regional electricity fuel mix. Consequently, each GJ of PCW replaces $<1$ GJ of primary fossil fuels for electricity generation (fossil replacement rate).

The incineration of PCW with electricity production overall does decrease the demand for primary fuels. However, due to the low fossil replacement rate, PCW can lead to a reduction in electricity emissions only if CC-PCW is much lower than CC-Elec. As shown in Table 4, this is not the case in any of the scenarios with incineration with electricity generation leading to net increases in emissions (up to $466 \mathrm{~g} \mathrm{C}$ per $\mathrm{kW} \mathrm{h}$ ), with higher emissions in the NoBio case due to the higher carbon content of PCW. PCW cascading can lead to emission reduction if the fossil replacement rate can be improved by increasing the efficiency of waste-toelectricity conversion, if baseline electricity generators have lower efficiency or if the carbon content of PCW is further reduced. ${ }^{48,51}$

\section{Discussion}

The main purpose of the model is to project the non-energy use and to study the possibilities for this sector to reduce its $\mathrm{CO}_{2}$ emissions. An emphasis has been placed on the potential use of biomass as well as various post-consumer plastic waste treatment options. A key outcome is the potentially significant contribution of biomass in this sector, leading to large emission reductions. In order to investigate the robustness of these results and to investigate the effect of important parameters on our findings, we have performed a sensitivity analysis. Furthermore, the results have also been compared with the outcomes of other relevant studies.

In the NEDE model, the non-energy final demand is driven by per-capita economic growth; the model allocates market shares of primary fuels per final product based on relative costs. Fig. 10 shows a sensitivity analysis performed on the use of biomass as well as the carbon emissions by 2100 when varying the projections for GDP per cap and energy prices (see Table 3 ) by $\pm 25 \%$ for the Bio scenario. As shown in Fig. 3, demand for non-energy products flattens out with increasing affluence, thus the final demand and resultant biomass use and emissions become less sensitive to changes in GDP per cap. Since the model allocates market shares of primary fuels per final product based on relative costs, the results heavily depend on the competitiveness of primary energy carriers. According to the model results, as fossil fuels become more expensive, biomass use increases as it is the marginal fuel. Consequently, the competitiveness of biomass is very sensitive to its price. As the price of individual fossil fuels changes, biomass use is affected to a lesser degree since other fossil fuels can also have marginal gains.

Emissions in 2100 are driven by coal use (especially in ammonia production), and consequently by its competitiveness with gas and biomass which are the marginal fuels. It is important to note that

Table 4 Details of baseline electricity generation, availability and carbon content (CC) of PCW, and emission effects of PCW incineration with electricity generation. NoBio and Bio cases in 2050 and 2100. Note: table may have rounding errors

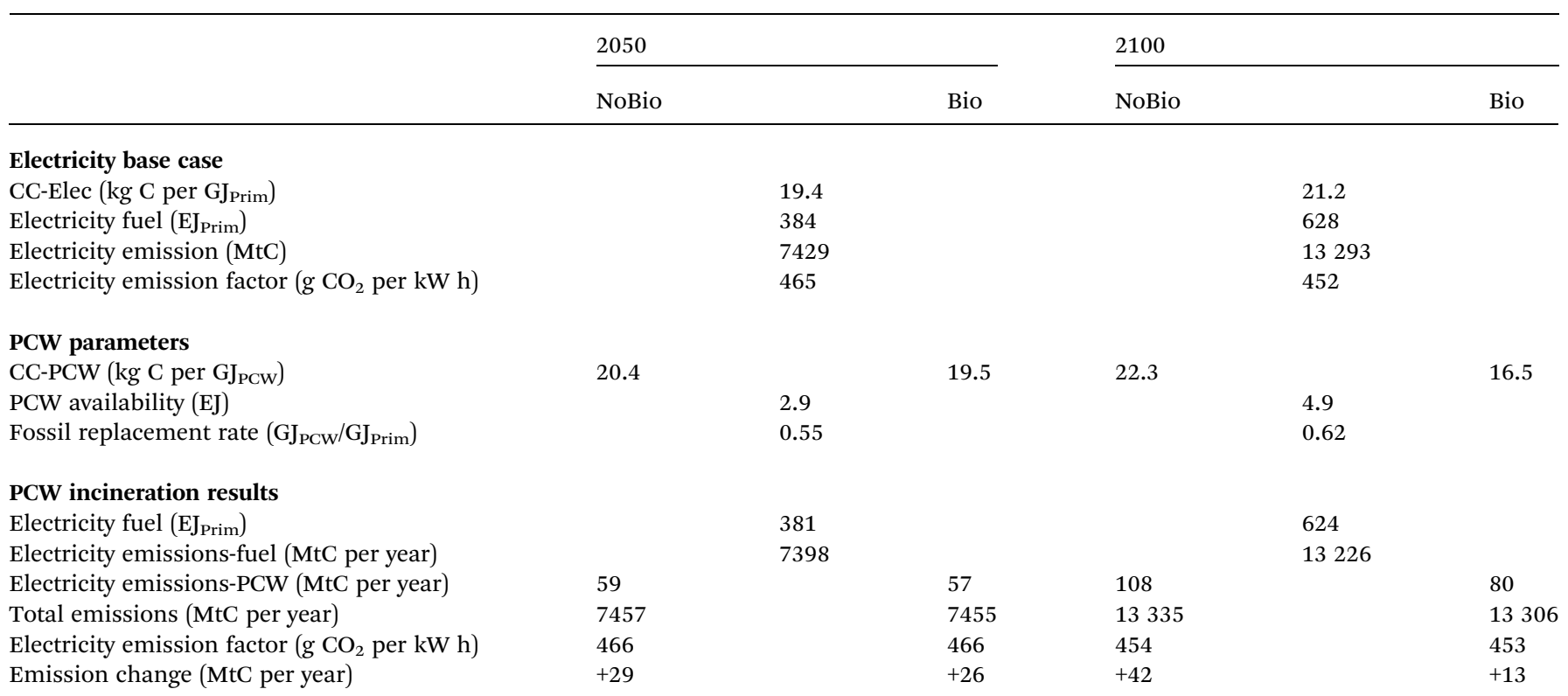


even in the case where the biomass price is $25 \%$ higher, the total emissions are still lower than that in the NoBio case.
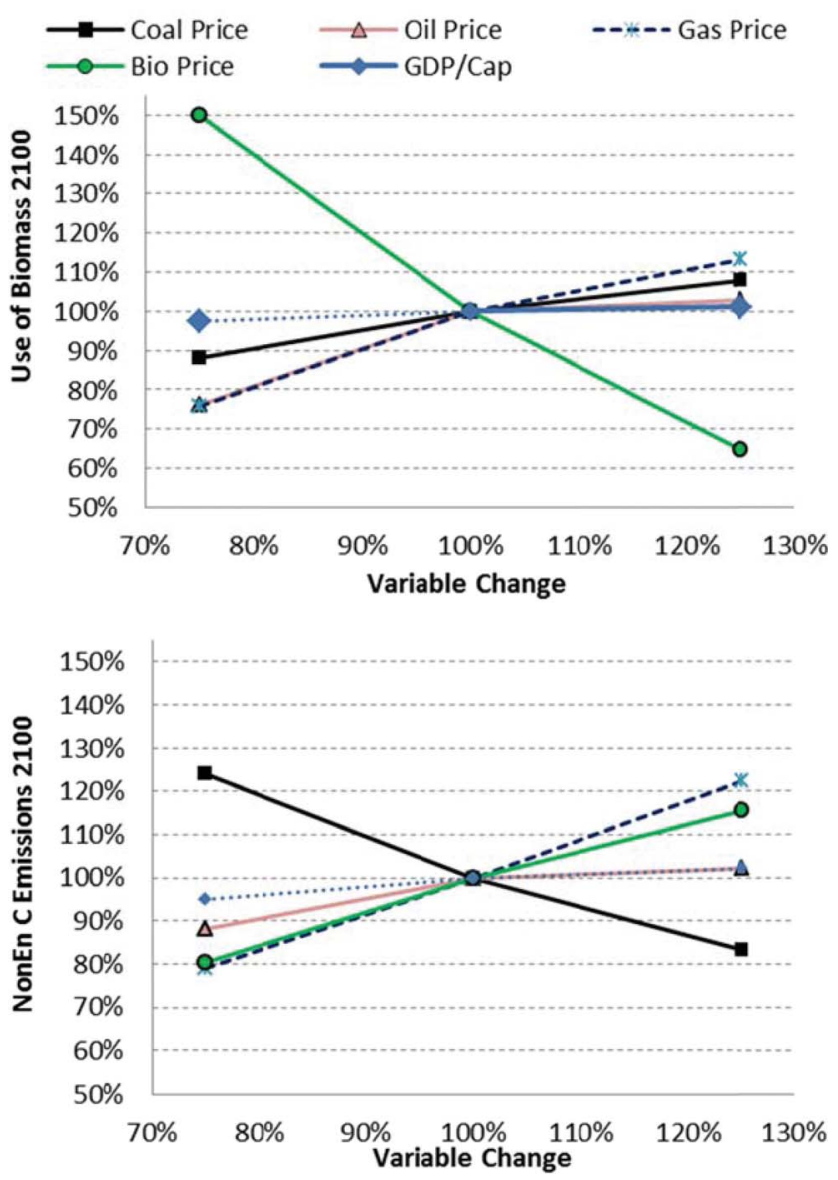

Fig. 10 Results of sensitivity analysis on use of biomass (top) and emissions (bottom) for 2100. Effect of energy carrier prices and per capita GDP (Bio case).

The model projects that all of the PCW available for mechanical recycling is used since it is considered a cheap method to reduce HVC demand. In order to assess how this may affect the conclusions of the model, Table 5 shows how the fossil and biomass energy requirements of the Bio scenario are affected when recycling routes are ignored. As expected the total primary energy demand increases. This increase comes from both biomass and fossil fuel use, which leads to an emission increase when recycling is ignored.

Table 5 Change in the non-energy sector's total biomass and fossil energy demand and its emissions when recycling is excluded (results shown for the Bio case, 2100)

\begin{tabular}{llll}
\hline & Bio case & No recycling & $\%$ \\
\hline Total biomass (EJ per year) & 45 & 52 & $+14 \%$ \\
Total fossil energy (EJ per year) & 54 & 64 & $+18 \%$ \\
Total primary energy (EJ per year) & 100 & 116 & $+15 \%$ \\
Emission (MtC per year) & 544 & 593 & $+9 \%$ \\
\hline
\end{tabular}

An inherent uncertainty of the NEDE model concerns the future projections of non-energy demand and the overall market structure. Demand has been modelled as a function of observed intensities of demand for non-energy products with respect to economic development. Earlier studies found meaningful relationships to support this hypothesis for bulk materials such as steel, cement, paper and aluminium. ${ }^{35,36,58}$ Besides economic growth, the availability of cheap feedstocks and newly installed large refinery capacities (Middle East, more recently shale gas in the USA), or the existence of innovative high value added sectors (Japan, Europe) are also factors determining non-energy demand. This explains why the fits are somewhat worse compared to other sectors. Furthermore, trade of non-energy products is not explicitly modelled. An attempt has been made to incorporate these dynamics in the NEDE model as the regional demand for each product depends both on economic development and energy prices (through a price-induced multiplier). Consequently, at any given GDP, regions with lower energy costs are going to have a relatively higher (production) demand. Institutional aspects of the non-energy sector and its intimate relation to oil and gas extraction capital are ignored, especially concerning the refinery products. Our methodology assumes that there is a given demand for these products, which should be met irrespective of oil and gas extraction and refining trends. Due to the "price ratio" assumptions of bio-based refinery products, the biomass use for this product is projected to be very high. The development of this price ratio is highly uncertain and based on limited current observations. Given the assumed relationship with economic development, a study highlighting how per capita demand before and after 2007 developed would provide valuable insight into the robustness of our method.

The results highlight a very high use of biomass in the nonenergy sector. This result is optimistic since it is assumed that no other competitive use of biomass for energy purposes exist. This high use reflects only the projected potential of biomass in the non-energy sector and it is important to investigate how this potential may be limited due to other biomass uses.

Though the model investigates carbon flows per non-energy product, the representation of emissions is simplified in order to maintain relevance and simplicity. Emissions of the nonenergy sector are difficult to model due to complex material and energy flows, with huge uncertainties in future projections. Furthermore, it is assumed that whatever carbon not emitted during feedstock conversion or incineration is accumulated indefinitely in non-energy products (and land-fills). Plastic waste degradation has been estimated at 1-5\% during a 100 year period. ${ }^{48}$ Thus this assumed accumulated carbon may have significant effects if the time period of the analysis were to be expanded, increasing the emissions of the NoBio case and improving the performance of the incineration scenarios.

Despite the uncertainties, the model compares well with other studies. Allwood et al. ${ }^{59}$ estimate carbon emissions from plastics production in 2006 at $136 \mathrm{MtC}$, while for the same year NEDE calculates the emissions at 139 MtC. Though the nonenergy use estimates between the NEDE model and the IEA statistics differ (see Section 2.2), the annual growth rate for global non-energy demand between 2010 and 2050 according to NEDE is $1.98 \%$, while the IEA-Energy Technology Perspectives baseline is $1.93 \% .^{4}$ The same IEA study also projects that carbon emissions related to non-energy use will more than double between 2007 and 2050, in agreement with our results under the NoBio scenario. Concerning the ability of biomass to penetrate 
into this sector, Gielen et al. ${ }^{60}$ estimate that biomass can account for $22 \%$ of the petrochemical sector in 2050 , which is in line with our $28 \%$ projection for the Bio scenario (Table 8 ).

\section{Conclusions}

This paper presented an analysis and possible future trajectories of non-energy demand and the associated emissions. Available data have been assessed and used to construct a simulation model able to project final demand, primary energy demand of different energy carriers under different scenarios and the magnitude of carbon flows.

Analysis of bottom-up data has highlighted inconsistencies in the IEA energy statistics concerning non-energy use; a conclusion which other studies have also drawn. ${ }^{20}$ The bottom-up data has been used to develop the NEDE model, a top-down simulation model for global long-term projections of the non-energy sector. The model assumes that the non-energy sector demand can be represented by a limited number of products which can be produced from primary fuels. Each fuel competes for a market share of the final product based on its costs, conversion costs and conversion efficiency.

The model is a significant step forward concerning the future assessment of the non-energy sector. The NEDE model can assess the dynamics of the non-energy sector and how its structure changes with time and economic development. Further, it provides projections of overall primary demand for non-energy as well as the potential of fuel switching as representative pathways for each product and fuel are included. In addition to explicit energy flows, carbon flows are also modelled, accounting for both emitted and accumulated carbon. The model can be used to assess how different scenarios such as climate policy and waste incineration with energy recovery affect non-energy demand and its emissions. Finally, the NEDE model is fully integrated in the IMAGE/TIMER integrated assessment model framework. Integrated assessment models usually model non-energy in secondary energy terms (as opposed to final energy in NEDE) thus ignoring effects of energy carrier conversion efficiency and have little detail due to complexities in different flows in the energy system. Important progress has been made with the NEDE model since the level of description is detailed enough to be relevant, and aggregated enough to be included in an integrated assessment model.

The model projects that global demand for non-energy will increase significantly from $30 \mathrm{EJ}$ today to over $100 \mathrm{EJ}$ by 2100 . HVC is projected to be the most important non-energy product, followed by refinery products and ammonia. Assuming only fossil fuel use, oil and natural gas are the main feedstocks for HVC until 2050. Subsequent oil price increases lead to replacement by coal and natural gas. Coal becomes increasingly important in the production of methanol and ammonia, replacing natural gas.

The use of biomass for non-energy purposes can significantly reduce fossil energy demand and emissions. Assuming only the use of fossil fuels, the annual emissions of non-energy increase from $163 \mathrm{MtC}$ per year in 2010 to $677 \mathrm{MtC}$ per year in 2100. However, biomass can supply over $40 \%$ of the total required primary energy, reducing emissions to $544 \mathrm{MtC}$ per year. The sensitivity analysis has shown that this result is robust since even if the price of biomass were $25 \%$ higher, the emissions would still be significantly lower than the
NoBio case. However, it is important to keep in mind that in this study, biomass does not compete for other energy services (biofuels, residential heating, etc.). Thus, this paper does not study the optimal use or the competition of biomass across various options in the energy system, but rather its potential in the non-energy sector alone.

Emissions can be further reduced by promoting fuel switching via climate policy. At a carbon tax rate of $\$ 100$ per $\mathrm{t} C$, the sector's emissions are projected to reduce to $433 \mathrm{MtC}$ per year and $367 \mathrm{MtC}$ per year by 2100 in the NoBio and Bio cases, respectively. This reemphasizes the importance of biomass at reducing emission abatement costs since the Bio case at no tax offers similar emission levels with those of the NoBio case at a $\$ 50$ per t $\mathrm{C}$ tax ( $534 \mathrm{MtC}$ per year).

Cascading uses of post-consumer waste do not necessarily reduce the total primary energy demand and emissions of nonenergy use. The model projects that when competing freely, all of the waste available for mechanical recycling is used. Back-tofeedstock recycling is marginal due to its high costs and energy requirements. The full recycle scenario showed that forcing back-to-feedstock recycling does not reduce energy demand and emissions compared to the Bio case. Mechanical recycling reduces total primary energy demand for feedstocks by $15 \%$, but affects emissions to a lesser extent since it has emissions of its own. If $30 \%$ of PCW is used as a feedstock for electricity production, though reducing the demand for primary energy carriers, it may increase the emissions of the power sector. This happens despite projections that coal becomes a significant primary fuel for electricity generation. The emission increase is due to the reduced efficiency of electricity generation from PCW with respect to fossil fuels. Emission reductions via this measure are possible with efficient waste-toelectricity technologies and avoiding the use of carbon intensive non-energy feedstocks. A summary of the carbon flows of all scenarios can be found in Table 10 .

In conclusion, the NEDE model indicates that energy and emissions reduction in the non-energy sector can profit most from fuel switching to biomass and avoiding the use of coal feedstocks. This may reduce the annual emissions by up to $20 \%$ in 2100. Post-consumer waste measures may reduce emissions only if recycling and cascading processes become more efficient. A similar analysis of other possible uses of biomass in the energy system is required in order to determine if biomass for non-energy use is the optimal option for reducing emissions.

\section{Appendix}

Table 6 Primary energy demand (including PCW) for non-energy products and HVC-heat as well as total demand for NoBio and Bio cases

\begin{tabular}{llllllll}
\hline & \multicolumn{2}{l}{ NoBio } & & & & Bio & \\
\cline { 2 - 5 } \cline { 7 - 8 } & 2010 & 2050 & 2100 & & 2010 & 2050 & 2100 \\
\hline HVC-net & $32 \%$ & $33 \%$ & $37 \%$ & & $32 \%$ & $32 \%$ & $39 \%$ \\
HVC-heat & $9 \%$ & $6 \%$ & $12 \%$ & $9 \%$ & $6 \%$ & $8 \%$ \\
Ammonia & $24 \%$ & $18 \%$ & $14 \%$ & $24 \%$ & $19 \%$ & $15 \%$ \\
Methanol & $5 \%$ & $7 \%$ & $6 \%$ & & $5 \%$ & $7 \%$ & $6 \%$ \\
Refinery products & $30 \%$ & $35 \%$ & $31 \%$ & & $30 \%$ & $36 \%$ & $32 \%$ \\
Total EJ & 29 & 63 & 107 & 29 & 65 & 109
\end{tabular}




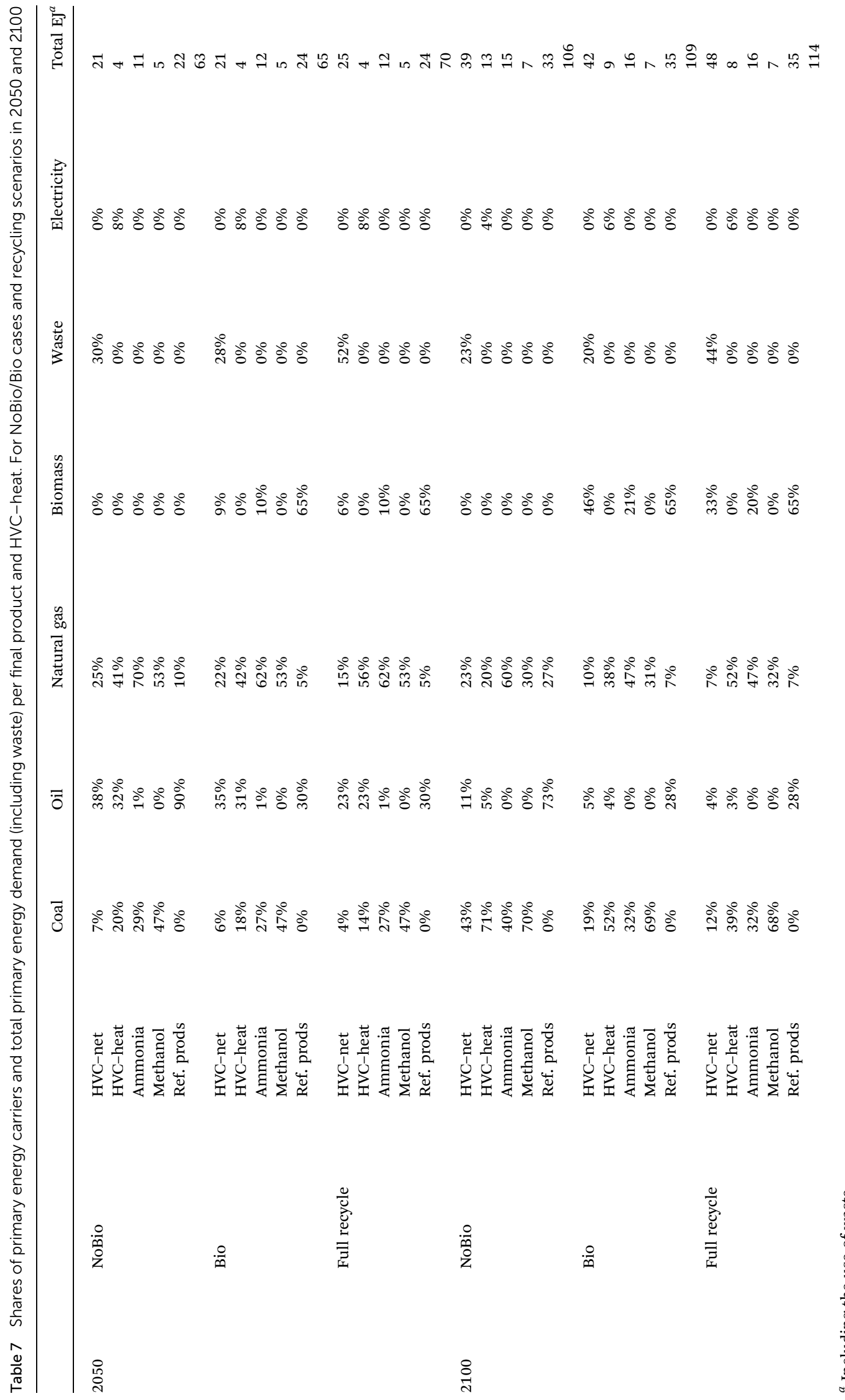




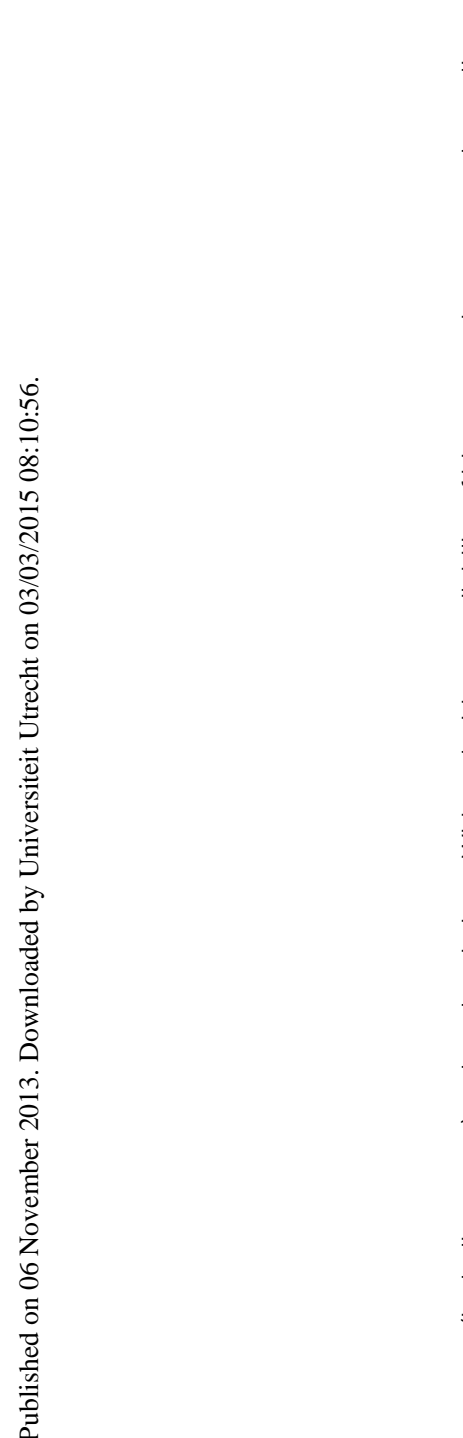

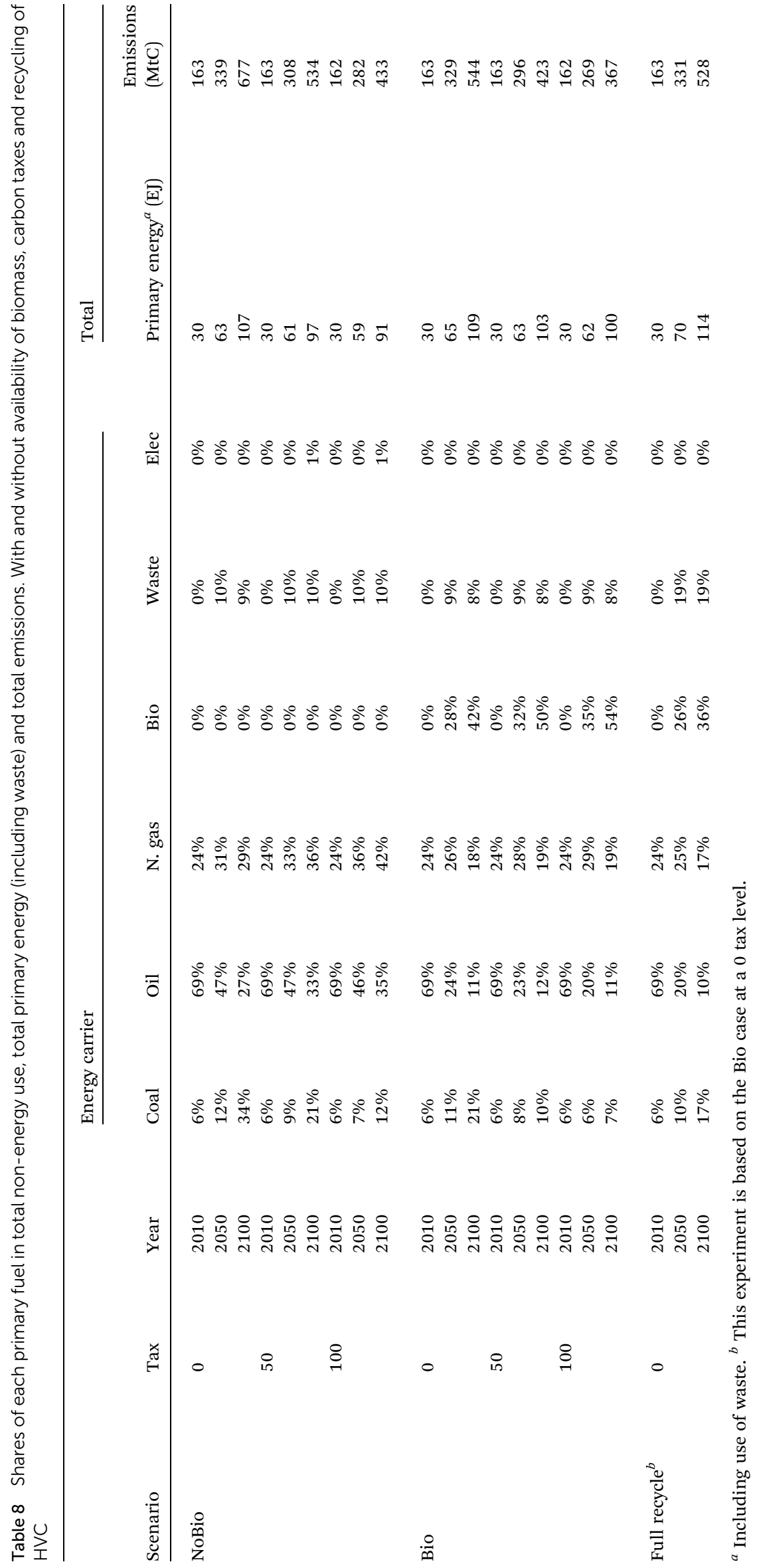


Table 9 Baseline (OECD Environmental Outlook) projections of shares of primary fuel for electricity generation according to the IMAGE/TIMER model

\begin{tabular}{llll}
\hline & 2010 & 2050 & 2100 \\
\hline Coal & $44 \%$ & $53 \%$ & $72 \%$ \\
Oil & $5 \%$ & $0 \%$ & $0 \%$ \\
N. gas & $16 \%$ & $16 \%$ & $2 \%$ \\
Biomass & $3 \%$ & $0 \%$ & $0 \%$ \\
Nuclear & $13 \%$ & $8 \%$ & $7 \%$ \\
Solar/wind & $3 \%$ & $14 \%$ & $13 \%$ \\
Hydro & $16 \%$ & $9 \%$ & $7 \%$ \\
Total (EJ Elec) & 72 & 211 & 387
\end{tabular}

Table 10 Annual and cumulative carbon flows for NoBio, Bio, fullrecycle, incineration and no-recycle scenarios

\begin{tabular}{|c|c|c|c|c|c|}
\hline \multirow[b]{2}{*}{ Flow type } & \multirow[b]{2}{*}{ Scenario } & \multicolumn{2}{|c|}{$\begin{array}{l}\text { Annual flows } \\
\text { (MtC per } \\
\text { year) }\end{array}$} & \multicolumn{2}{|c|}{$\begin{array}{l}\text { Cumulative flows } \\
\text { (MtC) }\end{array}$} \\
\hline & & 2050 & 2100 & 2050 & 2100 \\
\hline \multirow[t]{5}{*}{ Emitted } & NoBio & 339 & 677 & 8586 & 32105 \\
\hline & Bio & 329 & 544 & 8459 & 29662 \\
\hline & Full recycle & 331 & 528 & 8471 & 29704 \\
\hline & Incineration $^{a}$ & 356 & 557 & 8925 & 31306 \\
\hline & No recycle & 338 & 593 & 8637 & 30611 \\
\hline \multirow[t]{5}{*}{ Recycled } & NoBio & 102 & 162 & 1984 & 8812 \\
\hline & Bio & 91 & 101 & 1817 & 7087 \\
\hline & Full recycle & 202 & 242 & 3452 & 16192 \\
\hline & Incineration & 91 & 101 & 1817 & 7087 \\
\hline & No recycle & 0 & 0 & 0 & 0 \\
\hline \multirow[t]{5}{*}{ Accumulated } & NoBio & 634 & 1142 & 14638 & 61340 \\
\hline & Bio & 449 & 728 & 11991 & 43945 \\
\hline & Full recycle & 282 & 491 & 9567 & 30114 \\
\hline & Incineration & 392 & 648 & 10915 & 39072 \\
\hline & No recycle & 655 & 1015 & 16014 & 60911 \\
\hline
\end{tabular}

${ }^{a}$ Assumes bio-based PCW. Emission increases in electricity generation allocated to the non-energy sector.

\section{Acknowledgements}

We would like to thank the unnamed reviewers whose helpful comments contributed to improving the quality of this work. This work was conducted within the research program "Knowledge Infrastructure for Sustainable Biomass" and was funded by the Dutch ministries of 'Economic Affairs, Agriculture and Innovation' and 'Infrastructure and Environment'.

\section{References}

1 IEA, Definitions: Non-Energy Use, see also: http://www.iea.org/ stats/defs/origins/nonenuse.asp.

2 IEA, Key World Energy Statistics, OECD/IEA, Paris, France, 2012.
3 J. G. J. Olivier and J. A. H. W. Peters, $\mathrm{CO}_{2}$ from non-energy use of fuels: A global, regional and national perspective based on the IPCC Tier 1 approach, Resour., Conserv. Recycl., 2005, 45, 210-225.

4 IEA, Energy Technology Perspectives, IEA/OECD, Paris, 2010.

5 IEA, Energy Balances of OECD Countries, International Energy Agency, Paris, 2010.

6 L. Shen, E. Worrell and M. K. Patel, Present and future development in plastics from biomass, Biofuels, Bioprod. Biorefin., 2010, 4(1), 25-40.

7 V. Dornburg, B. G. Hermann and M. K. Patel, Scenario Projections for Future Market Potentials of Biobased Bulk Chemicals, Environ. Sci. Technol., 2008, 42, 2261-2267.

8 G. Chen and M. K. Patel, Plastics Derived from Biological Sources: Present and Future: A Technical and Environmental Review, Chem. Rev., 2011, 112(4), 2082-2099.

9 T. Ren, B. Daniels, M. K. Patel and K. Blok, Petrochemicals from oil, natural gas, coal and biomass: Production costs in 20302050, Resour., Conserv. Recycl., 2009, 52(12), 653-663.

10 IPCC, IPCC Special Report on Renewable Energy Sources and Climate Change Mitigation, Prepared by Working Group III of the Intergovenmental Panel on Climate Change, Cambridge University Press, Cambridge, United Kingdom and New York, NY, USA, 2011.

11 D. Saygin, M. K. Patel, E. Worrell, C. Tam and D. Gielen, Potential of best practice technology to improve energy efficiency in the global chemical and petrochemical sector, Energy, 2011, 36(9), 5779-5790.

12 V. Dornburg and A. P. C. Faaij, Cost and $\mathrm{CO}_{2}$-emissions reduction of biomass cascading: Methodological aspects and case study of SRF poplar, Clim. Change, 2005, 71(373), 408.

13 S. M. Al-Salem, P. Lettieri and J. Baeyens, Recycling and recovery routes of plastic solid waste (PSW): A review, Waste Manag., 2009, 29, 2625-2643.

14 IEA, Chemical and petrochemical sector - Potential of best practice technology and other measures for improving energy efficiency, OECD/IEA, Paris, 2009.

15 IEA, World Energy Outlook 2011, OECD/IEA, Paris, 2011.

16 D. Gielen, J. Fujino, S. Hashimoto and Y. Moriguchi, Biomass strategies for climate policies?, Clim. Pol., 2002, 2, 319-333.

17 IEA, World Energy Outlook 2012, OECD/IEA, Paris, France, 2012.

18 IEA, World energy model - methodology and assumption, IEA/ OECD, Paris, 2009.

19 M. K. Patel, M. L. Neelis, D. Gielen, J. G. J. Olivier, T. Simmons and J. Theunis, Carbon dioxide emissions from non-energy use of fossil fuels: Summary of key issues and conclusions from the country analyses, Resour., Conserv. Recycl., 2005, 45, 195-209.

20 M. Weiss, M. L. Neelis, M. C. Zuidberg and M. K. Patel, Applying bottom-up analysis to identify the system boundaries of non-energy use data in international energy statistics, Energy, 2008, 33(11), 1609-1622.

$21 \mathrm{MNP}$, Integrated modelling of global environmental change, An overview of IMAGE 2.4, Netherlands Environmental Assessment Agency (MNP), Bilthoven, The Netherlands, 2006. 
22 D. van Vuuren, M. G. J. Den Elzen, P. Lucas, B. Eickhout, B. J. Strengers and B. J. van Ruijven, Stabilizing greenhouse gas concentrations at low levels: an assessment of reduction strategies and costs, Clim. Change, 2007, 81(2), 119-159.

23 M. Hoogwijk, A. Faaij, B. De Vries and W. C. Turkenburg, Exploration of regional and global cost-supply curves of biomass energy from short-rotation crops at abandoned cropland and rest land under four IPCC SRES land-use scenarios, Biomass Bioenergy, 2009, 33(1), 26-43.

24 D. van Vuuren, J. van Vliet and E. Stehfest, Future bio-energy potential under various natural constraints, Energy Policy, 2009, 37, 4220-4230.

25 T. Ren, M. K. Patel and K. Blok, Olefins from conventional and heavy feedstocks: Energy use in steam cracking and alternative processes, Energy, 2006, 31(4), 425-451.

26 Ullmann, Ullmann's Encyclopedia of Industrial Chemistry, in Electronic Release, Wiley-VCH, 2007.

27 MI, Applications of Methanol, see also: http://www. methanol.org/Methanol-Basics/Methanol-Applications.aspx, 2013.

28 A. Chauvel and G. Lefebvre, Petrochemical processes, technical and economic characteristics; part 1: synthesis-gas derivatives and major hydrocarbons, Paris, Technip edn, 1989.

29 PBL, Regions of the IMAGE model, Bilthoven, The Netherlands, 2013, see also http://themasites.pbl.nl/tridion/ en/themasites/image/background/regions/index-2.html.

30 MI, Global Methanol Capacity, Methanol Institute, Burssels, Belgium, 1999-2003.

31 OGJ, International Survey of Ethylene from Steam Crackers 1997, Penwell Corporation, Houston, TX, USA, 1997-2012.

32 OGJ, Worldwide Refineries, Penwell Corporation, Houston, TX, USA, 1997-2012.

33 USGS, Minerals Yearbook: Nitrogen, US Geological Survey, Reston VA, USA, 1996-2012.

34 IEA, World Energy Statistics, International Energy Agency, 1996-2007.

35 H. Groenenberg, K. Blok and J. P. van der Sluijs, Projection of energy-intensive material production for bottom-up scenario building, Ecol. Econ., 2005, 53, 75-99.

36 D. P. van Vuuren, B. J. Strengers and B. de Vries, Long-term perspectives on world metal use - a systems-dynamic model, Resour. Policy, 1999, 25, 239-255.

37 B. de Vries, D. van Vuuren, M. G. J. den Elzen and M. A. Janssen, The Targets IMage Energy Regional (TIMER) Model: Technical Documentation, RIVM, Bilthoven, 2001.

38 D. P. Van Vuuren, B. J. Strengers and H. J. M. De Vries, Longterm perspectives on world metal use - a systems-dynamics model, Resour. Policy, 1999, 25, 239-255.

39 T. Ren and M. K. Patel, Basic petrochemicals from natural gas, coal and biomass: Energy use and $\mathrm{CO}_{2}$ emissions, Resour., Conserv. Recycl., 2009, 53, 513-528.

40 S. J. Gerssen-Gondelach, D. Saygin, B. Wicke, M. K. Patel and A. P. C. Faaij, Competing uses of biomass - Assessment and comparison of the performance of bio-based heat, power, fuels and materials, Renewable Sustainable Energy Rev., 2013, submitted.
41 C. Hamelinck and M. Hoogwijk, Future Scenarios for First and Second Generation Biofuels, Ecofys, Utrecht, 2007.

42 C. Liptow and A. Tillman, A Comparative Life Cycle Assessment Study of Polyethylene Based on Sugarcane and Crude Oil, J. Ind. Ecol., 2012, 16(3), 420-435.

43 M. L. Neelis, M. K. Patel, D. Gielen and K. Blok, Modelling $\mathrm{CO}_{2}$ emissions from non-energy use with the non-energy use emission accounting tables (NEAT) model, Resour., Conserv. Recycl., 2005, 45, 226-250.

44 B. J. van Ruijven, D. van Vuuren and B. de Vries, The potential role of hydrogen in energy systems with and without climate policy, Int. J. Hydrogen Energy, 2007, 32(12), 1655-1672.

45 D. Saygin, D. Gielen, M. Draeck, E. Worrell and M. K. Patel, Assessment of the technical and economic potentials of biomass use for the production of steam, chemicals and polymers, Renew. Sustain. Energy Rev., 2012, submitted.

46 DOE, Energy and Environmental Profile of the U.S. Chemical Industry, Department of Energy, Washington DC, USA, 2000.

47 MMSA, MMSA Global Methanol Supply and Demand Balance, 2005-2010, MMSA, Singapore, 2013, see also http://www. methanol.org/Methanol-Basics/Resources/MMSA-GlobalMethanol-Supply-and-Demand.aspx.

48 D. Lazarevic, E. Aoustin, N. Buclet and N. Brandt, Plastic waste management in the context of a European recycling society: Comparing results and uncertainties in a life cycle perspective, Resour., Conserv. Recycl., 2010, 55, 246259.

49 L. Shen, E. Nieuwlaar, E. Worrell and M. K. Patel, Life cycle energy and GHG emissions of PET recycling: change oriented effects, Int. J. Life Cycle Ass., 2012, 16, 522536.

50 F. Perugini, M. L. Mastellone and U. Arena, A Life Cycle Assessment of Mechanical and Feedstock Recycling Options for Management of Plastic Packaging Wastes, Environ. Prog., 2005, 24(2), 137-154.

51 A. M. Ragossnig, C. Wartha and A. Kirchner, Energy efficiency in waste-to-energy and its relevance with regard to climate control, Waste Manage. Res., 2008, 26, 70-77.

52 V. Dornburg, A. P. C. Faaij and B. Meuleman, Optimising waste treatment systems, Part A: Methodology and technological data for optimising energy production and economic performance, Resour., Conserv. Recycl., 2006, 49, 68-88.

53 M. L. M. Broeren, D. Saygin and M. K. Patel, Forecasting global developments in the basic chemical industry for environmental policy analysis, Energy Policy, 2014, 64, 273287.

54 IPCC, 2006 Guidelines for National Greenhouse Gas Inventories, Prepared by the National Greenhouse Gas Inventories Programme, IGES, Japan, 2006.

55 M. Weiss, M. L. Neelis and M. K. Patel, Non-Energy Use and Related $\mathrm{CO}_{2}$ Emissions in Germany: $A$ Carbon Flow Analysis with the NEAT Model for the Period of 1990-2003, Copernicus Institute, Utrecht, 2007. 
56 P. Al-Riffai, B. Dimaranan and D. Laborde, Global Trade and Environmental Impact Study of the EU Biofuels Mandate, International Food Policy Research Institute, Washington, DC, 2010.

57 OECD, OECD Environmental Outlook to 2050: The Consequences of Inaction, OECD, Paris, 2012.

58 E. Lysen, B. De Vries, K. Blok, M. K. Patel, M. Weiss, S. Joosen et al., Assessment of the interaction between economic and physical growth, Netherlands Environmental Assessment Agency, Bilthoven, 2006.

59 J. M. Allwood, J. M. Cullen and R. L. Kilford, Options for Achieving a $50 \%$ Cut in Industrial Carbon Emissions by 2050, Environ. Sci. Technol., 2010, 44(6), 1888-1894.

60 E. Taibi, D. Gielen and M. Bazilian, The potential for renewable energy in industrial applications, Renewable Sustainable Energy Rev., 2012, 16, 735-744. 